\begin{tabular}{|r|c|c|c|c|c|}
\hline MUNIBE Antropologia-Arkeologia & $n^{0} 68$ & $217-236$ & DONOSTIA & 2017 & ISSN 1132-2217 • elSSN 2172-4555 \\
\hline
\end{tabular}

\title{
La aldea del Hierro Inicial del Cerro de San Vicente (Salamanca, España): Resultados de las excavaciones entre 1990 y 2006 a la luz de algunos debates actuales
}

\author{
The Early Iron Age village of Cerro de San Vicente (Salamanca, Spain): \\ Archaeological findings from the 1990-2006 excavations in view of some current debates
}

PALABRAS CLAVES: Excavación arqueológica; procesos formativos; organización social; Primera Edad del Hierro; Meseta Central. GAKO-HITZAK: Indusketa arkeologikoa; eraketa-prozesuak; antolaketa soziala; Lehen Burdin Aroa; Iberiar Goi Lautada. KEY WORDS: Archaeological excavation; formation processes; social organization; Early Iron Age; Iberian Central Meseta.

\section{Antonio BLANCO-GONZÁLEZ ${ }^{(1)}$, Carlos MACARRO ALCALDE(2) y Cristina ALARIO GARCíA ${ }^{(3)}$}

\section{RESUMEN}

Este artículo recoge algunos de los principales resultados de las excavaciones arqueológicas efectuadas entre 1990 y 2006 en el yacimiento de la Primera Edad del Hierro (800-400 cal AC) del Cerro de San Vicente (Salamanca). El trabajo aborda dos cuestiones mal conocidas, centrándose en las últimas ocupaciones del asentamiento, por ser las mejor investigadas: a) los procesos de formación y acumulación de restos en una aldea con arquitectura de barro; y b) una caracterización social de sus habitantes. La anatomía interna de este asentamiento muestra la persistencia de usos y la superposición de desechos y estructuras. Las viviendas carecen de enseres domésticos, aparecen colmatadas con adobes y en ocasiones incendiadas. Respecto a la organización social, se detectan síntomas de división interna: las casas con atrio y sus dependencias auxiliares se cercan. Las estrategias agrarias complejas constatadas pudieron haber facilitado la acumulación de riqueza por algunas familias, dentro de una organización social heterárquica.

\section{LABURPENA}

Artikulu honetan, 1990 eta 2006 artean Cerro de San Vicente parke arkeologikoko (Salamanca) Lehen Burdin Aroko (K.a. $800-400$ urte kal) aztarnategian egindako indusketa arkeologiko nagusietako batzuk biltzen dira. Kokalekuaren azken okupazioak ardatz hartuta, horiek baitira gehien ikertu direnak, ongi ezagutzen ez diren bi gai aztertzen dira lan honetan: a) buztinezko arkitektura duen herrixka batean hondarrak eratzeko eta metatzeko prozesuak; eta b) bertako biztanleen ezaugarri sozialak. Kokaleku horren barne-anatomiak agerian uzten du erabileren jarraitutasuna eta hondakinen eta egituren gainezarpena. Etxebizitzetan ez dago etxeko gauzarik, adobez beteta agertzen dira, eta, batzuetan, erreta. Antolaketa sozialari dagokionez, barne-banaketaren aztarnak ikusten dira: ataridun etxeek eta gela osagarriek itxiturak dituzte. Egiaztatutako nekazaritza-estrategia konplexuek familia batzuek aberastasuna metatzeko bidea eman zezaketen, antolaketa sozial heterarkiko batean.

\section{ABSTRACT}

This paper draws on the results of excavations over the last few decades (1990-2006) at a tell-like fortified village dated to the Early Iron Age (c. 800-400 cal BC) in central Iberia: Cerro de San Vicente (Salamanca, Spain). The article tackles two main issues overlooked and disregarded in recent literature: a) formation processes in this sort of sites featuring mud architecture; and b) a finer-grained characterization of lifestyles at these villages in social, economic and political terms. A critical appraisal of intra-site spatial arrangements shows two ubiquitous rationales that permeated practices everywhere: redundancy in the use of spaces (with fixed indoor and outdoor zones) and accumulation of matter (foundations, hearths, soils, wall plasterwork, etc.). Painstaking stratigraphic recording has shed fresh light upon abandonment dynamics. Thus, roundhouses were carefully sealed with adobes and they exhibit proofs of intense fires, probably lit on purpose. Living quarters featured no systemic assemblages or 'de facto refuse' so that the 'Pompeii premise' was not in operation here. As for socio-economic dynamics, the last occupations produce evidence for complex agropastoral systems (including short-fallow agriculture and draught animals) and a strong material investment in dwellings, which suggests a trend towards differential access to resources and intra-site social division within an increasingly ranked community. Thus, the uppermost phases feature stone-fenced domestic compounds of aggregated buildings around roundhouses with porches, wall paintings and the oldest sewerage device in the northern half of Iberia. Many aspects, including chronology, remain ill-defined, yet ongoing fieldwork is to challenge these shortcomings.

\footnotetext{
(1) GIR PREHUSAL. Departamento de Prehistoria, $\mathrm{H}^{\mathrm{a}}$. Antigua y Arqueología. Facultad de Geografía e Historia. Universidad de Salamanca.

C/ Cervantes s/n, 37002 Salamanca. ablancoglez@gmail.com

(2) Área de Urbanismo. Ayuntamiento de Salamanca. C/ Iscar Peyra 24-26, 37002 Salamanca. cmacarro@aytosalamanca.es

(3) Arqueóloga autónoma. cristinaalario@hotmail.com
} 


\section{1.- INTRODUCCIÓN}

El inicio de la Edad del Hierro en la península lbérica (c. 800-400 cal AC) se caracterizó por transformaciones a muy distinto nivel: tanto tecnológicas, como demográficas, en las creencias y en las formas de vivir. En las tierras del interior y norte peninsulares tales cambios fueron profundos, y marcaron un punto de inflexión (Ruiz-Gálvez, 1992, 1998; Álvarez-Sanchís, 1999, 2003; Parcero Oubiña, 2002; González Ruibal, 2006-7; Romero Carnicero et al., 2008; Ruiz Zapatero, 2009; Delibes de Castro y Romero Carnicero, 2011; Blanco García, 2017). En los años 1990 una serie de intervenciones arqueológicas modernas y ambiciosas establecieron las bases del conocimiento actual (Blasco Bosqued et al. 1991; Delibes de Castro et al. 1995b). La investigación arqueológica ha avanzado lentamente desde la síntesis de Fernández-Posse (1998). En la última década los trabajos de campo han sido esporádicos: sondeos preventivos parcialmente publicados (p.e. Dávila, 2007; Morín y Urbina, 2012; Torres Rodríguez, 2013; Rodríguez Díaz et al., 2015a) y excepcionales memorias de excavaciones en área abierta (p.e. Rodríguez Díaz, 2004; Picazo y Rodanés, 2009; Misiego Tejeda et al., 2013). Con estos mimbres se han propuesto lecturas sociales y económicas de ámbito regional, aplicables a distintas sociedades en diversos estadios (Álvarez-Sanchís, 1999, 2003; Parcero Oubiña, 2002; González-Ruibal, 2006-7, 2009; Sastre et al., 2010; González García et al., 2011; Esparza Arroyo, 2011; López Jiménez, 2011; Torres Rodríguez, 2013; Rodríguez Díaz et al., 2015b; Arnáiz Alonso, 2017).

Pese a los logros alcanzados, algunas trayectorias históricas del interior peninsular durante el primer milenio AC carecen aún de un esbozo social, económico y político coherente. En concreto, este trabajo aborda dos aspectos poco investigados: ¿qué ha quedado del hábitat de entonces, que representa el primer asentamiento aldeano en la región? y ¿qué pueden decirnos esos retazos materiales sobre la organización social y política de aquellas gentes? Ambos problemas, el de la génesis del registro arqueológico doméstico y el de su interpretación, presentan graves carencias en el caso de las comunidades del centro-occidente de la cuenca del Duero, o ámbito cultural de El Soto de Medinilla (Álvarez-Sanchís, 1999, 2003; Ruiz Zapatero, 2007, 2009; Romero Carnicero et al., 2008; Delibes de Castro y Romero Carnicero, 2011; Ruiz Zapatero y Álvarez-Sanchís, 2015; Blanco García, 2017). Nuestra contribución pretende examinar información relevante y discutirla a la luz de los conocimientos y debates actuales. El artículo versa sobre los resultados de sucesivas campañas de excavación sistemática en el Cerro de San Vicente (Salamanca) entre 1990 y 2006. Tales hallazgos han sido presentados de forma concisa en una breve guía divulgativa (Macarro Alcalde y Alario García, 2012) pero, salvo alguna contribución reciente (Blanco-González et al., 2017), hasta ahora no han sido discutidos en detalle. Aquí se evaluará cómo se acumularon los voluminosos restos que encontramos en la aldea del Cerro de San Vicente. A partir de ello, se ensayará una caracterización matizada y flexible de las sociedades del final de la Primera Edad del Hierro en el sector occidental del valle del Duero.

\section{EL CERRO DE SAN VICENTE}

\subsection{Localización}

El Cerro de San Vicente (en adelante CSV) es el más occidental de los altozanos sobre los que se emplaza la ciudad vieja de Salamanca (Fig. 1). Se trata de un relieve amesetado de arenisca eocena con una altitud de 805 m s.n.m. sobre la margen derecha del río Tormes (Fig. 2). La erosión fluvial modeló este teso como una lengua de terreno de cima aplanada. Su cumbre alberga una densa y compleja superposición de edificios de barro correspondientes a una aldea de la Primera Edad del Hierro (c. 800-400 cal AC). El altozano está delimitado en tres de sus flancos por escarpes: los más verticales son el noroeste y el meridional, totalmente vertical y con unos $30 \mathrm{~m}$ de desnivel respecto al río Tormes, que fluye a sus pies (Figs. 1B y 2). Hacia el este la pendiente está abancalada y llega hasta la Vaguada de La Palma, una zona húmeda hoy desecada, pero que en tiempos prehistóricos pudo haber procurado agua y buenos terrenos hortícolas. Hacia el noreste el teso presenta un estrangulamiento fácilmente accesible, por lo que el asentamiento protohistórico se dotó aquí de una muralla que encerraba una superficie de 1,3 hectáreas. Fuera de esta barrera defensiva han sido documentadas algunas estructuras domésticas del Primer Hierro, por lo que la aldea alcanzó unas 2,5 hectáreas en su momento de mayor extensión. El yacimiento se encuentra dentro del Conjunto Histórico de Salamanca (1951), inmediato al bien inmueble de la ciudad vieja de Salamanca inscrito en la Lista del Patrimonio Mundial de UNESCO (1988).

El teso reunía unas condiciones idóneas: de fácil defensa al tiempo que estaba emplazado junto al principal curso de agua de la región y cerca de las campiñas sedimentarias más feraces. El enclave se localiza además en una zona vadeable del río Tormes, a tan solo $400 \mathrm{~m}$ del puente romano altoimperial atravesado por el Iter ab Emerita Asturicam o Vía de la Plata, cuya traza es aún reconocible en las inmediaciones (Gillani y Santonja, 2007) (Fig. 1B). Esta vía romana coincide con una ruta de comunicación sur-norte mucho más antigua (Ruiz-Gálvez, 1998), cuya importancia en la llegada de productos importados del suroeste peninsular (los primeros instrumentos de hierro, objetos suntuarios o la alfarería torneada) ha sido reiteradamente señalada (Martín Valls, 1998; Romero Carnicero y Ramírez Ramírez, 1996; Esparza Arroyo, 2011; Álvarez Sanchís et al., 2016). 


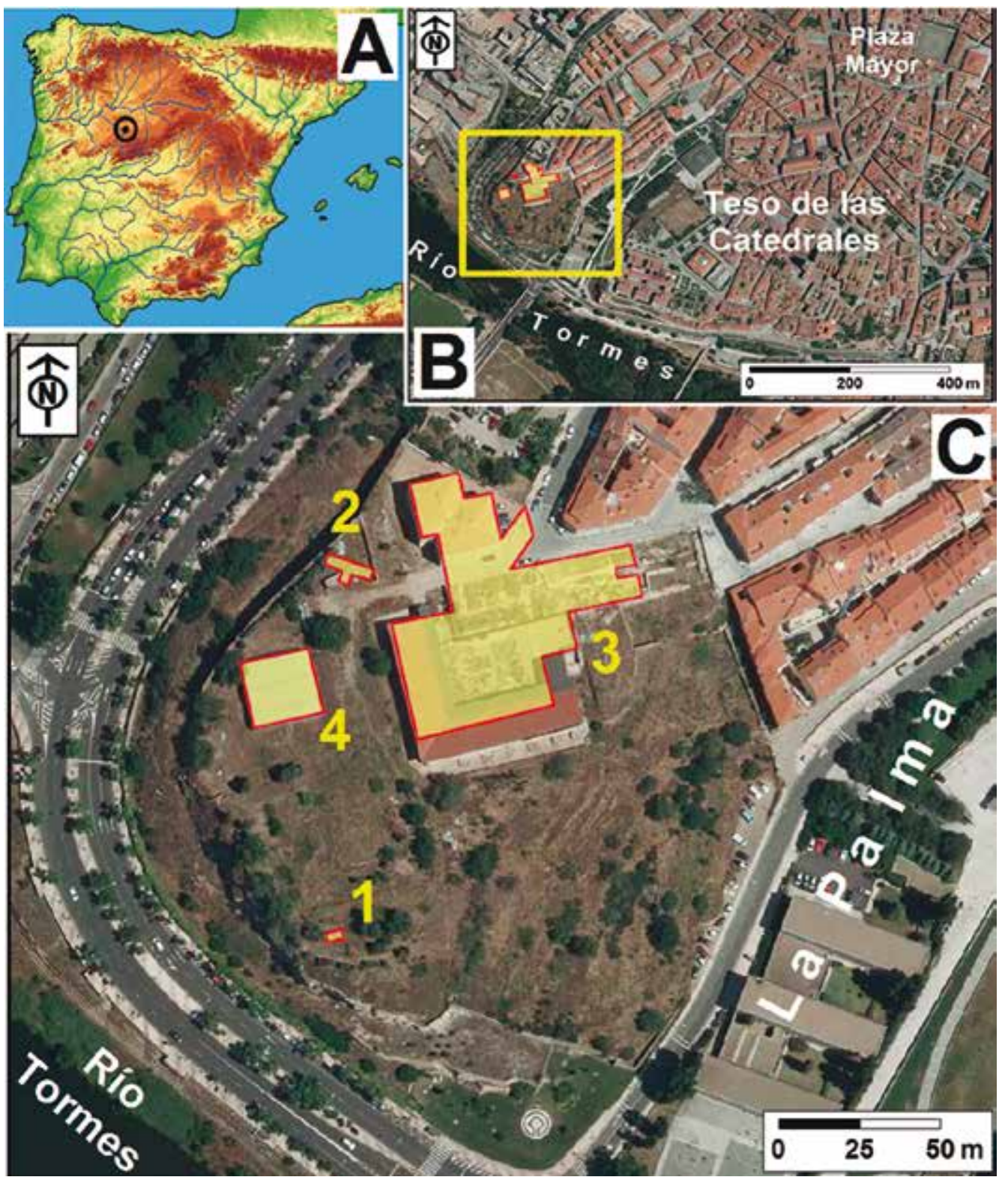

Fig. 1. A) Localización del Cerro de San Vicente en la península Ibérica. B) Situación en la ciudad vieja de Salamanca. C) Detalle del teso con los sectores excavados (en amarillo): (1) sondeo de 1990; (2) sondeos de 1992; (3) excavación del claustro del convento y aledaños entre 1992-2003; (4) cata en área abierta de 2006. / A) Location of Cerro de San Vicente in the Iberian Peninsula. B) The site in the old city of Salamanca. C) Detail of the hillock with excavated sectors (in yellow): (1) test-pit in 1990; (2) trench in 1992; (3) excavation of the cloister and surroundings in 1992-2003; (4) open area excavation in 2006 .

\subsection{Historia de la investigación}

El asentamiento presenta una estratificación de unos 2-3 $m$ de potencia del Primer Hierro muy bien preservada. Esta secuencia protohistórica ha sido afectada por algunas remociones puntuales: actividades de la Segunda Edad del Hierro; las construcciones plenomedievales y modernas del Convento de San Vicente, que dan nombre al teso; y las obras de fortificación realizadas por las tropas napoleónicas durante la Guerra de la Independencia. Se han recogido algunos fragmentos cerámicos de la Edad del Bronce (Cogotas I) pero no se han detectado niveles de ocupación previos a la Edad del Hierro. El crecimiento demográfico probablemente generó la necesidad de trasladarse a un solar más holgado. Por ello, el asentamiento se trasladó en el siglo IV a.C. al cercano Teso de las Catedrales, al otro lado de la Vaguada de la Palma (Fig. 1B), donde se construyó un castro amurallado del Hierro II y posteriormente la ciudad romana de Salmantica (Martín Valls et al., 1991; Benet Jordana, 2001; Alario García y Macarro Alcalde, 2007), abandonándose definitivamente el CSV avanzado el siglo III a.C. Por fortuna, el altozano de San Vicente no acogió ocupaciones romanas ni medievales, que habitualmente practicaban subsolaciones profundas para cimentar sus edificios, por lo que los restos protohistóricos a menudo se han preservado en condiciones óptimas.

La ocupación de la Edad del Hierro fue reconocida por primera vez por Juan Maluquer de Motes (1951) a partir de unos pocos materiales cerámicos y metálicos 


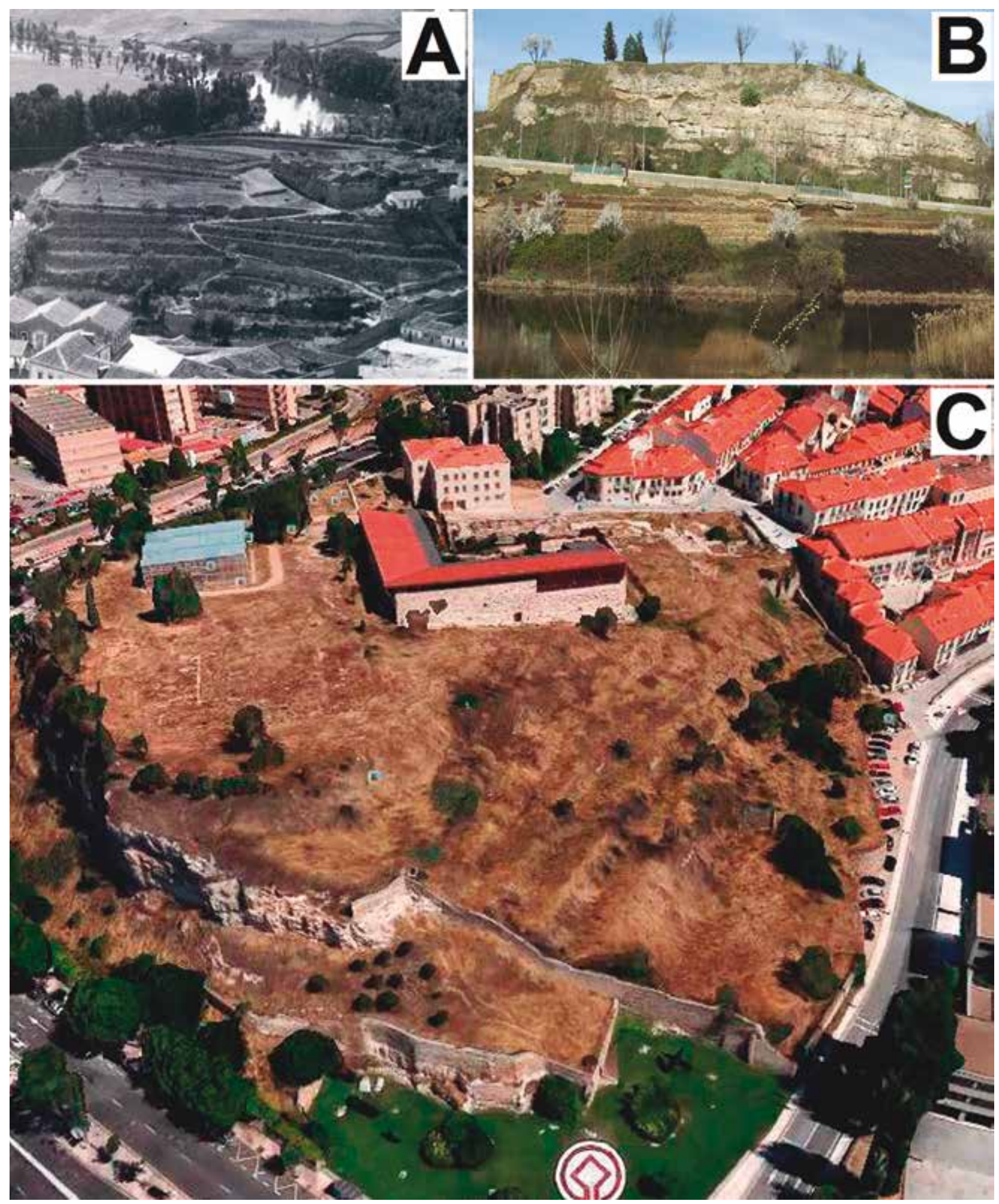

Fig. 2. A) El Cerro de San Vicente a comienzos del siglo XX desde el este, con el río Tormes al fondo (Archivo Gombau, Ayto. de Salamanca). B) Vista actual desde el sur, con el río Tormes en primer término. C) Vista aérea oblicua desde el sur. Se aprecia el centro de interpretación sobre el claustro conventual (edificio en "L" con techo rojo) y la estructura con techo azulado que cubre la cata de 2006. / A) Cerro de San Vicente in the early twentieth century from the east, with the Tormes River in the background (Photograph: Gombau Archive, Council of Salamanca). B) Present-day view from the south, with the Tormes River at the forefront. C) Oblique aerial view from the south. Note the interpretation centre (red-roofed building with " $L$ " plan) and the open-area excavation on display (blue-roofed building). 
rescatados al construirse en 1949 una residencia de la Universidad Pontificia de Salamanca, finalmente demolida en el año 2004. Posteriormente, la cultura material recuperada fue comparada con la de El Soto de Medinilla (Valladolid), permitiendo así asignarla al mismo grupo cultural (Martín Valls et al., 1991; Benet y López Jiménez, 2008: 168; Esparza Arroyo, 2011: 22-23). Las primeras excavaciones arqueológicas comenzaron en 1990. Desde entonces se han sucedido diversas intervenciones arqueológicas: unas para evaluar la extensión y naturaleza arqueológica del sitio (con fondos públicos); otras de carácter preventivo (financiadas por promotores privados); y más recientemente para su acondicionamiento museográfico. La memoria de licenciatura de uno de nosotros (Macarro Alcalde, 1999) recopiló la información disponible hasta ese momento, dotando al lugar de una primera lectura histórica, que trabajos posteriores han permitido matizar y complementar (Macarro Alcalde y Alario García, 2012; Blanco-González et al., 2017).

Aproximadamente un tercio del yacimiento protohistórico ha sido objeto de excavaciones sistemáticas entre 1990 y 2006 (Fig. 1B). En todas esas intervenciones se ha empleado el habitual sistema de registro estratigráfico de contexto único o de Harris. Algunas de las estructuras exhumadas en 2006 han sido consolidadas y protegidas con una cubierta acristalada y una pasarela metálica para su visita pública. Sobre los restos del claustro conventual se ha construido un centro de interpretación del yacimiento, que complementa la visita de los restos arquitectónicos expuestos.

\section{PRINCIPALES RESULTADOS DE LOS TRA- BAJOS DE CAMPO}

Este apartado presenta de forma sintética algunos de los hallazgos más relevantes para las dos cuestiones planteadas en este artículo: cómo se acumularon los restos arqueológicos y cómo pueden ser interpretados.

\subsection{Sondeo de 1990}

En 1990 se efectuó un sondeo inicial de $15 \mathrm{~m}^{2}$ en el límite meridional de la plataforma superior del altozano (Fig. 1C y 3A) para evaluar la potencia, naturaleza y grado de conservación de los restos protohistóricos. Bajo niveles superficiales revueltos en el siglo XIX se detectó una sucesión de estructuras domésticas y un cenizal, agrupados en cinco fases de ocupación protohistórica (Fig. 3C). El techo de la secuencia presenta una vivienda circular (casa 6) de adobes - es decir, ladrillos de barro y paja moldeados y secados al sol - y otro edificio de planta indeterminada, de los que se excavaron sólo las dos fases de ocupación más superficiales (fases IV y V). Esta vivienda permitió caracterizar la arquitectura doméstica del sitio. La casa 6 durante la fase IV era circular de $5 \mathrm{~m}$ de diámetro, no se detectaron banco corrido, hogar, ni objetos en su interior (Fig.
3B). Su muro estructural conservaba una única hilada de adobes a soga, y su paramento interior exhibía un enlucido rojizo. Al excavar el suelo se reconocieron 17 finísimas capas arcillosas (de entre $3 \mathrm{~mm}$ y 1,5 cm) con un grosor total de $12,5 \mathrm{~cm}$, algunas con retazos de pintura ocre. En el umbral de entrada apareció un pequeño hoyo circular cuyas paredes había sido delimitadas con piedras de arenisca (Fig. 3B). Estaba relleno de una tierra rojiza y numerosos fragmentos de estucos de pared blancos con motivos pintados en negro - entre los que destaca uno con triángulos (Fig. 3D) - junto a restos cerámicos. Al exterior, esta vivienda presentaba un atrio o vestíbulo trapezoidal solado con adobes. En su posterior fase $\mathrm{V}$ la casa 6 exhibía banco corrido y un hoyo de poste calzado con piedras. Su entrada deparó otra cista subcuadrangular, también delimitada con losas de arenisca y rellena de tierra rojiza con restos de adobe descompuesto, restos óseos animales y fragmentos cerámicos.

La excavación del exterior de la casa 6 ofreció resultados igualmente inesperados. La entrada de la vivienda presentaba un vestíbulo trapezoidal de adobes orientado al este, y su espacio inmediato se integraba dentro de un recinto pavimentado, delimitado por el este por una linde de grandes bloques de arenisca (Fig. 3B), interpretada como el cimiento de una estructura de madera. Bajo el terrazo se reconocieron unos $3 \mathrm{~m}$ lineales de canaleta de desagüe de pequeñas lajas de pizarra hincadas y cubiertas, que buzaba hacia el sur (Fig. 3B). Se conocen desagües de pizarra de similar técnica en yacimientos extremeños de los siglos VI-V a.C., como en los edificios monumentales de La Mata (Campanario, Badajoz) (Rodríguez Díaz, 2004: 159, fig. 47) y Cancho Roano (Zalamea de la Serena, Badajoz) (Celestino Pérez, 1996: 299 y 307) o en el asentamiento rural de Cerro Manzanillo (Villar de Rena, Badajoz) (Rodríguez Díaz et al., 2009: 90-92). El caso salmantino es el más septentrional conocido hasta el momento en Iberia y su fecha es imprecisa, en torno al siglo VI a.C.

No se profundizó en toda la cata, sino que se sondeó el cenizal adyacente, de $2 \mathrm{~m}$ de espesor, hasta la roca madre (Fig. 3C). Este sondeo buscaba obtener una primera secuencia diacrónica, que permitiera caracterizar la cultura material y conseguir muestras orgánicas para datar por radiocarbono. Como se puede apreciar (Tabla 1) las dataciones de ${ }^{14} \mathrm{C}$ obtenidas, todas ellas según el método convencional (ninguna se procesó mediante AMS) quedan comprometidas por algunas deficiencias del muestreo y por imperfecciones en la curva de calibración. Así, las muestras recogidas en todos los casos fueron macrorrestos botánicos carbonizados (carbón vegetal), sin caracterización taxonómica ni tafonómica. Ello dificulta reconocer si en algún caso pudo tratarse de muestras de vida corta (tallos, corteza), o si fueron secciones internas de troncos de quercíneas, es decir, muestras de vida larga que pudieran haber dejado de absorber carbono décadas antes de incorporarse al cenizal. A ello se une la escasa precisión del tramo 

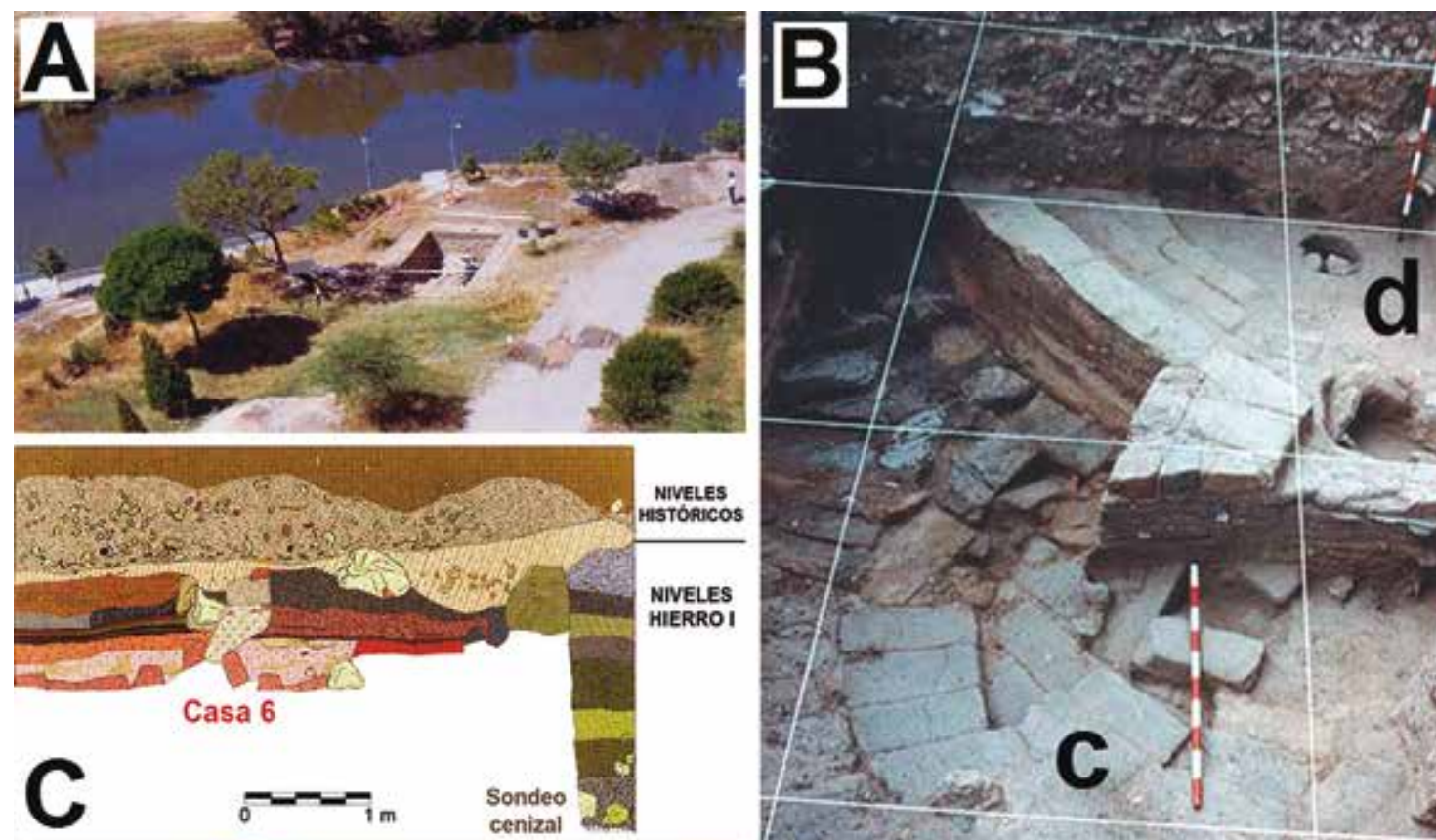

NIVELES

HIERROI

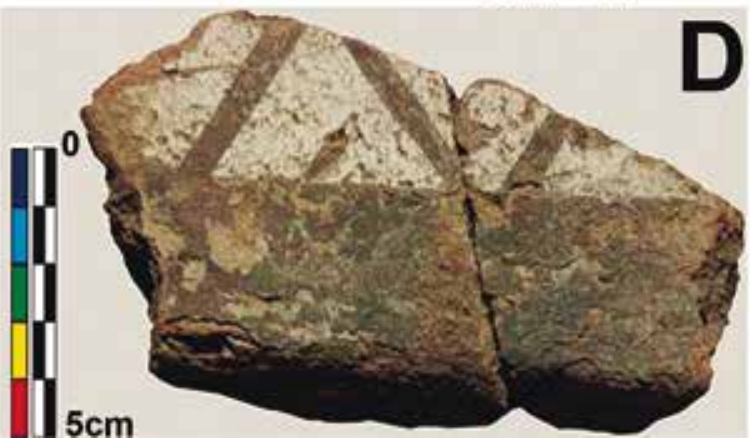

Fig. 3. Sondeo de 1990. A) vista desde el norte. B) Interior de la cata, mostrando una cerca de bloques de arenisca (a), una canaleta de pizarra (b), un terrazo de adobes (c) y la casa 6 con la fosa interior (d). C) Sección estratigráfica. D) Porción de enlucido ocultado en la fosa de la casa 6. / Test-pit in 1990. A) Overview from the north. B) Interior of the trench, showing a fence of boulders demarcating a compound (a), a drain pipe of slate slabs (b), an adobe-paved outdoor courtyard (c), roundhouse 6 with entrance pit (d). C) Stratigraphic section. D) Fragment of painted plaster deposited in a shallow pit within roundhouse 6.

\begin{tabular}{|c|c|c|c|c|c|}
\hline Ref. laboratorio & Material & Contexto & Edad BP & $\delta 13 C \%$ & Intervalo calibrado (cal AC) a $2 \sigma$ \\
\hline Beta-78721 & Carbón & $\begin{array}{l}\text { 1990. Cenizal exterior junto a casa 6, zona } \\
\text { alta (Fase IV, UE 16). }\end{array}$ & $2150 \pm 60$ & -25 & $370-40$ \\
\hline Beta-77445 & Carbón & $\begin{array}{l}\text { 1990. Cenizal exterior junto a casa 6, zona } \\
\text { intermedia (Fase III, UE 30). }\end{array}$ & $2450 \pm 70$ & -25 & $770-400$ \\
\hline Beta-77447 & Carbón & $\begin{array}{l}\text { 1990. Cenizal exterior junto a casa 6, zona } \\
\text { baja (Fase I, UE 61). }\end{array}$ & $2320 \pm 80$ & -25 & $760-680(7.1 \%), 670-610(3.4 \%), 600-190(84.8 \%)$ \\
\hline Beta-98135 & Carbón & $\begin{array}{l}\text { 1994-96. Zona del claustro medieval. } \\
\text { Cenizal exterior (Fase III, UE 87). }\end{array}$ & $2430 \pm 50$ & -25 & $760-680(21.1 \%), 670-400$ (74.3\%) \\
\hline Beta-98136 & Carbón & $\begin{array}{l}\text { 1994-96. Nivel sobre la muralla } \\
\text { protohistórica (Fase II, UE 73). }\end{array}$ & $2290 \pm 80$ & -25 & $\begin{array}{c}750-680(3.3 \%), 670-640(1.1 \%), 560-150(90.3 \%), 140-110 \\
(0.7 \%)\end{array}$ \\
\hline CSIC - 2072 & Carbón & $\begin{array}{l}\text { 2006. Casa 1, nivel de incendio interior } \\
\text { (Fase Illa, UE 140b). }\end{array}$ & $2583 \pm 30$ & $-25.5 \pm 0.2$ & $820-750$ (88.9\%), 690-660 (2.6\%), 640-590 (3.9\%) \\
\hline CSIC - 2126 & Carbón & $\begin{array}{l}\text { 2006. Casa 5, nivel de derrumbe interior } \\
\text { (Fase III, UE 521b). }\end{array}$ & $2541 \pm 39$ & $-25.0 \pm 0.2$ & $810-540$ \\
\hline Ua-34086 & Carbón & $\begin{array}{l}\text { 2006. Cenizal exterior junto a casa 4, zona } \\
\text { intermedia (Fase III, UE 419). }\end{array}$ & $2535 \pm 40$ & -25 & $810-540$ \\
\hline
\end{tabular}

Tabla 1: Fechas de radiocarbono del Cerro de San Vicente, calibradas usando Oxcal 4.3 con la curva Intcal13 (Reimer et al., 2013). / Radiocarbon assays from Cerro de San Vicente, calibrated using Oxcal 4.3 and the Intcal13 curve (Reimer et al., 2013). 

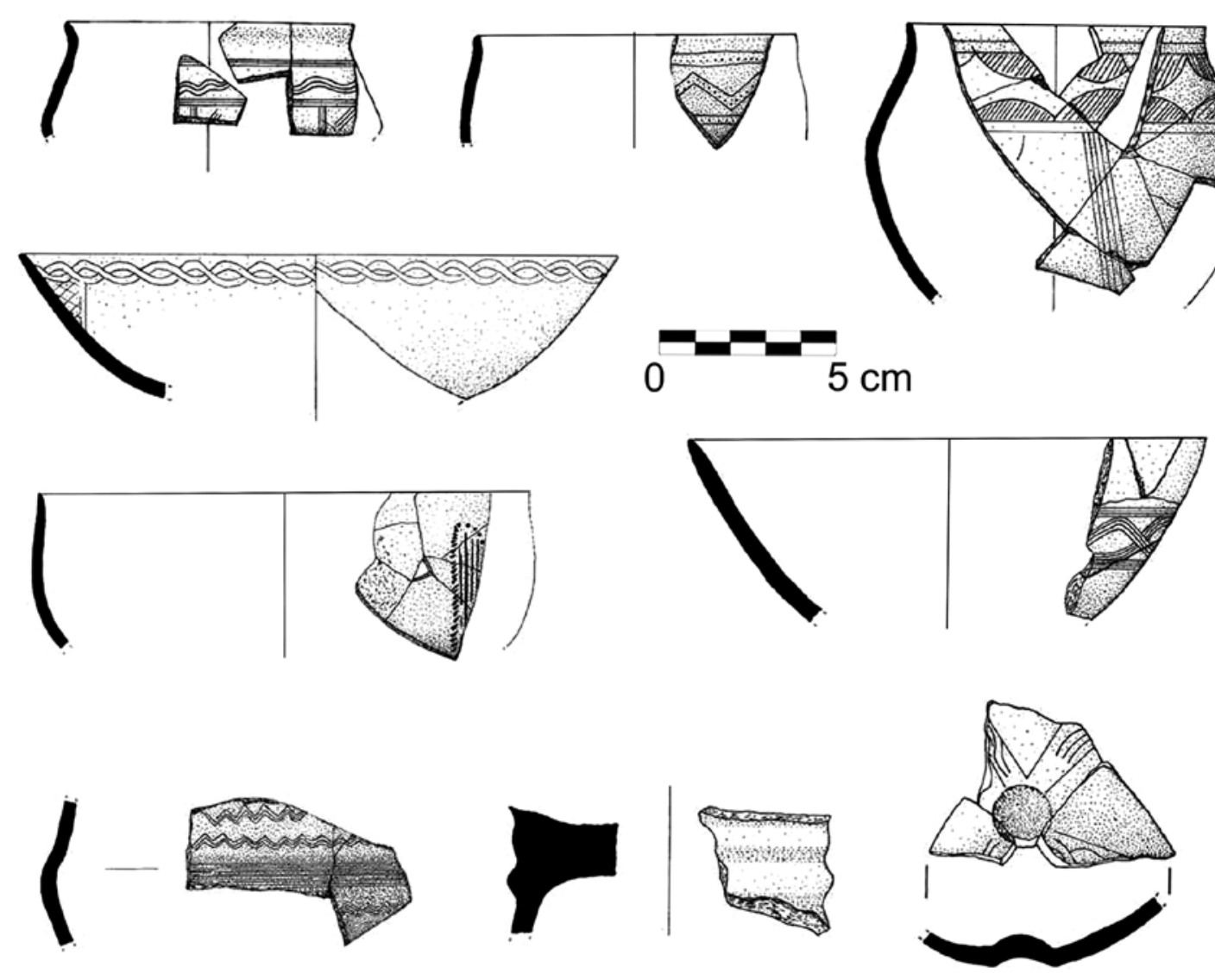

Fig. 4. Vajilla cerámica fina a mano con decoración a peine, de la zona superior de la secuencia. / Hand-made ceramic fineware with combed motifs, from the uppermost layers.

horizontal de la curva de calibración conocido como la 'meseta de Hallstatt' (800-400 cal AC). Los niveles superiores (UUEE 6, 9, 15, 16, 19) con abundantes desechos cerámicos y óseos estaban asociados a la mencionada casa 6. En este tramo final de la secuencia (fase III) predomina la cerámica fina incisa e impresa, sobre todo a peine (Fig. 4). La datación del tramo final del basurero por ${ }^{14} \mathrm{C}$ (Beta-78721) sitúa los últimos aportes de desechos en torno al siglo IV cal AC (Tabla 1). La muestra Beta-77445 de la zona intermedia del basurero ofrece un rango calibrado cuyo extremo más antiguo coincide con la muestra subyacente Beta-77447 y su valor más reciente es mucho más antiguo que el de Beta-77447. Así, Beta-77445 podría ser un residuo carbonizado errático de ocupaciones previas, atrapado en un nivel más joven. También pudiera tratarse de una porción interna de tronco longevo, afectado por el problema de la madera vieja. La ausencia de identificación taxonómica impide precisar más. Por debajo se sucedían otros lentejones cenicientos (UUEE 30, 60, 61 y 62) hasta el suelo geológico, con cerámicas pintadas poscocción, impresas a peine y puntilladas. De la UE 61, que cubría el nivel basal UE 62, se recuperó la muestra Beta-77447 para datar el fondo de la secuencia. La fundación del asentamiento ocurrió con anterioridad a la muerte del vegetal, acaecida a partir de c. 600 cal AC (con un 85\% de probabilidad) o, con menor certidumbre (10.5\%), en el siglo y medio previo.

\subsection{Campañas entre 1992 y 2006}

En este periodo se realizaron sucesivas excavaciones y sondeos en distintos puntos de la zona noreste del teso (años 1992-1996 y 2000-2003). Estas intervenciones ofrecieron dos novedades principales: a) una visión más amplia de la trama del vecindario protohistórico, aún preservado entre las zanjas de cimentación de los muros históricos; y b) el reconocimiento de la muralla del Primer Hierro. Respecto al caserío, lo más destacable fue la excavación durante 2001-2002 de la zona del claustro del convento de San Vicente, que, entre los cimientos medievales y modernos, procuró una imagen horizontal suficientemente amplia para apreciar la articulación de unos edificios con otros. Se exhumaron así las plantas parciales de unas diez viviendas superpuestas, correspondientes a los niveles más antiguos de la aldea (Fig. 5). Además, la necesidad de alcanzar la roca madre para cimentar el centro de interpretación permitió profundizar en la secuencia, complementándose así la visión diacrónica. Esto mostró que las casas redondas (más frecuentes) y rectangulares habían convivido en esta aldea desde su fundación. Se comprobó que las viviendas carecían de utensilios en su interior y en algunos casos habían sufrido violentos incendios (Fig. 6). El caserío no seguía ninguna planificación rígida; las viviendas salpicaban el interior de la aldea dejando espacios libres entre los que se acomodaba 

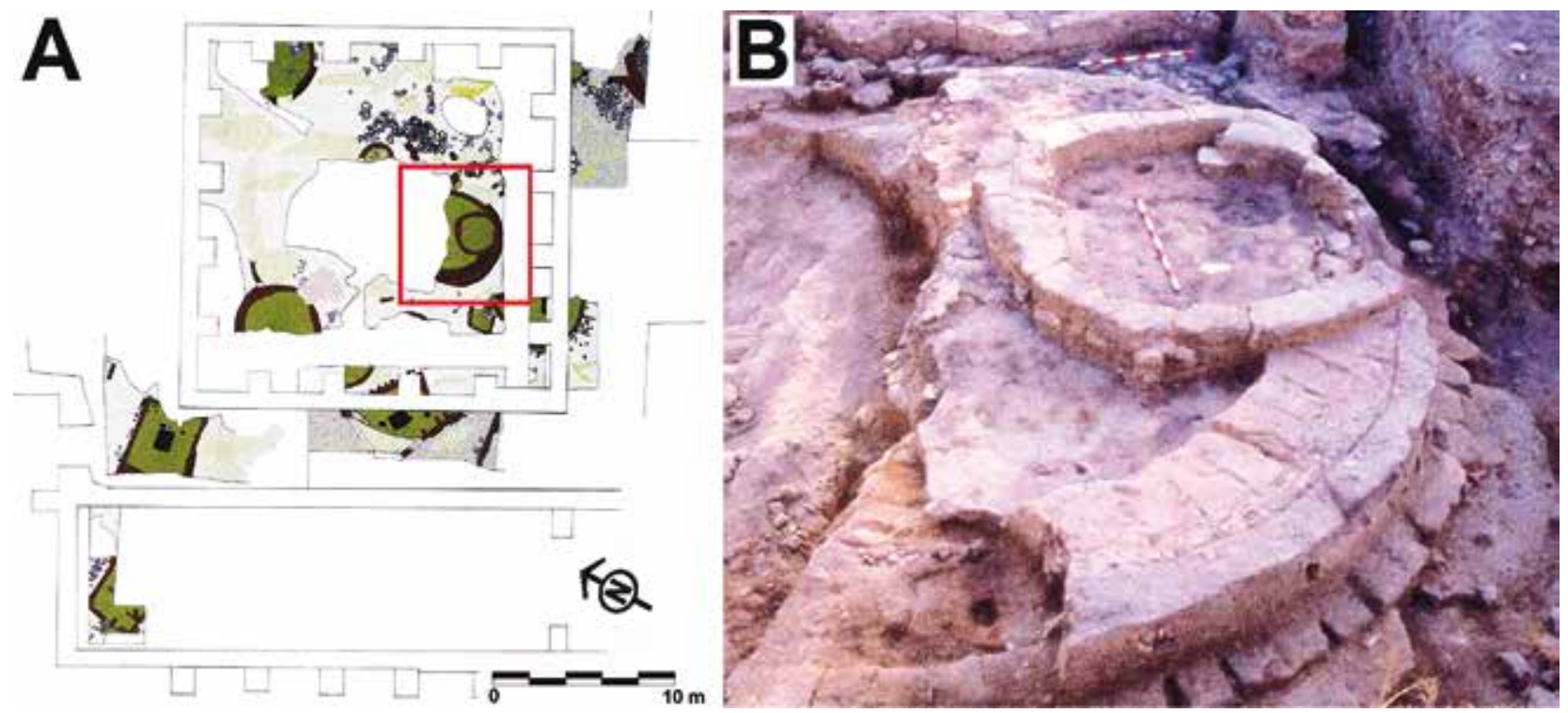

Fig. 5. A) Restos del Hierro Inicial en la excavación de 2000-2001 en el claustro conventual. B) Estructura auxiliar superpuesta a casa circular de adobe (recuadradas en rojo en A). / A) Early Iron Age remains unearthed at the cloister in 2000-2001. B) Small mud-brick building superimposed to an adobe roundhouse (red inset in A).

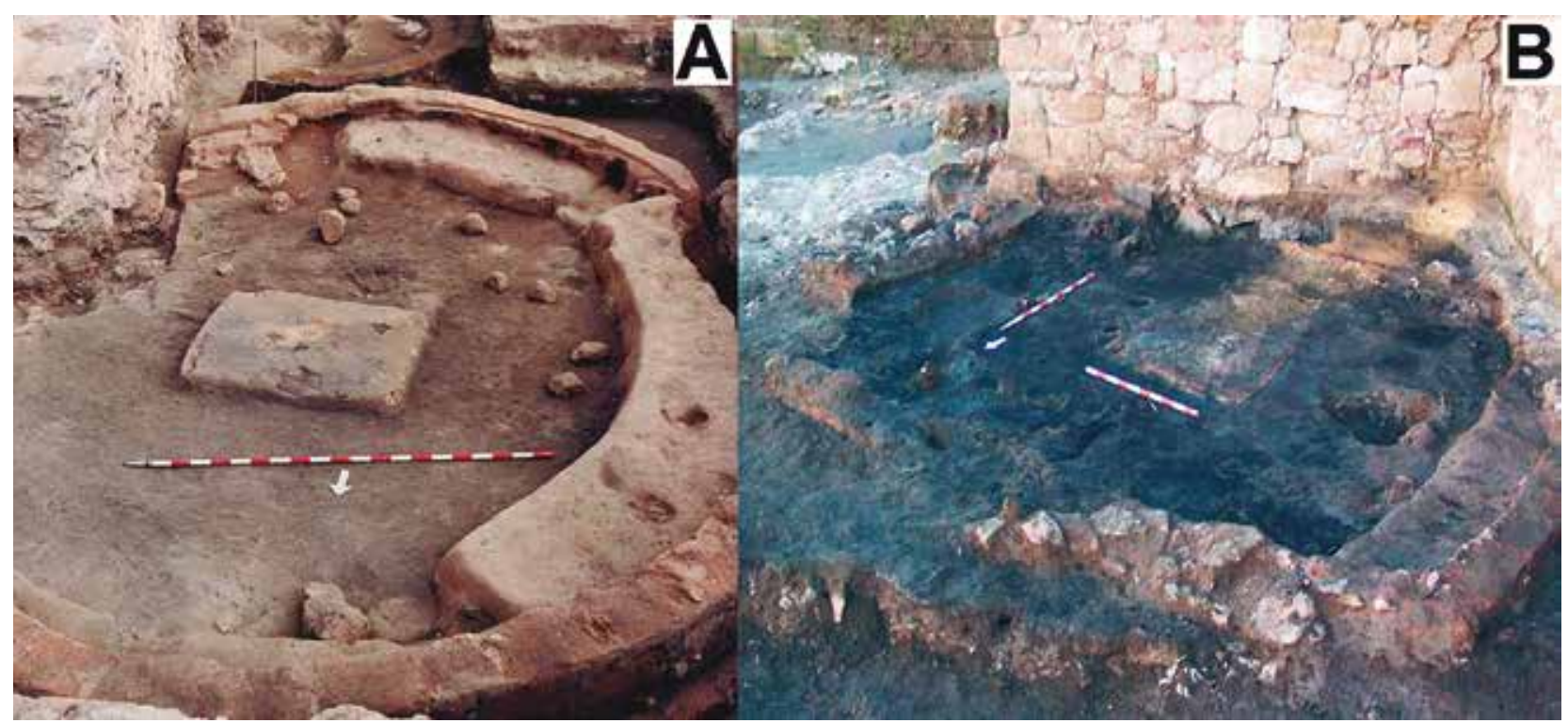

Fig. 6. Viviendas vacías y quemadas de la base de la secuencia: A) casa circular con banco, hogar y suelo termoalterados; B) casa rectangular con potente nivel de incendio. / Conflagrated dwellings devoid of items from the oldest phases: A) roundhouse whose bench, hearth and soil exhibit thermoalteration; B) rectangular house covered by a thick ashy stratum.

la deambulación, así como diversas actividades al aire libre (especialmente el vertido de desperdicios domésticos) y donde se ubicaban diversas edificaciones menores. Así, además de los basureros -ya documentados en 1990- se reconocieron otras construcciones anexas rectangulares y circulares más pequeñas, de función desconocida, pero similares a las encontradas en asentamientos coetáneos del valle medio del Duero, donde se relacionan con almacenes, trojes o despensas (Palol y Wattenberg, 1974; Delibes de Castro et al., 1995b; Romero Carnicero et al., 2008).
Algo más al norte y fuera ya del complejo conventual, diversos sondeos preventivos de 1994-1996 y 2003 identificaron los cimientos de la muralla de la aldea del Primer Hierro. Pese a su destrucción por las edificaciones modernas y contemporáneas, aún pudieron reconocerse sus cimientos en unos 35 m (Fig. 7A). Los restos conservados son de 2 a $3 \mathrm{~m}$ de grosor y hasta 1,4 $\mathrm{m}$ de altura, y la planta original, ligeramente arqueada, pudo cerrar el acceso estrangulado del cerro con unos $90 \mathrm{~m}$ de largo (Fig. 7B). El basamento de esta muralla se realizó con grandes bloques de arenisca y pizarra, con un 
alzado de tierra y ripio entre paramentos de arcilla bien decantada (de adobe o tapial). Esta técnica es conocida en otros asentamientos del ámbito soteño (Romero Carnicero et al., 2015). En particular, la aldea de La Corona/El Pesadero (Manganeses de la Polvorosa, Zamora) cerraba su flanco occidental mediante una muralla con cimiento de bloques de cuarcita y dos paramentos de adobes a soga que embutían un amasijo de adobes (Misiego Tejeda et al., 2013: 207-214, láms. 90-95). Y en el yacimiento de Soto de Medinilla es bien conocida la muralla erigida íntegramente con adobes dispuestos a soga en los paramentos externos (Romero Carnicero et al., 2015: 552-554). Durante las intervenciones de estos años en CSV se obtuvieron dos muestras de ${ }^{14} \mathrm{C}$ (Tabla 1): Beta-98136 verificó la antigüedad protohistórica de la muralla y Beta-98135 permitió plantear nuevas dudas sobre la cronología elaborada con argumentos cronotipológicos, ya que ofreció cierta probabilidad (21\%) de haber comprendido los siglos VII ó VIII cal AC.

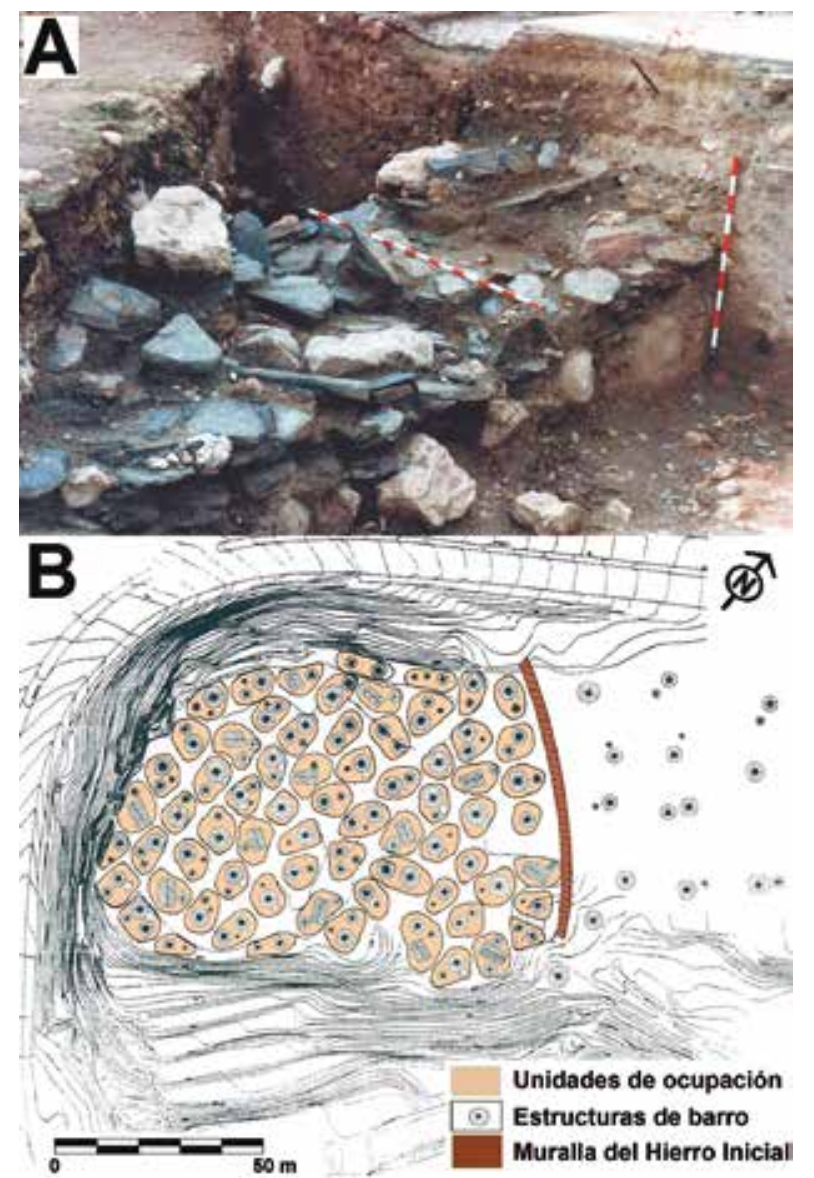

Fig. 7. A) Cimentación de piedra de la muralla terrera detectada en 19941996. B) Recreación hipotética de la aldea, a partir de lo investigado. / A) Stone foundation of the village's earthen wall, uncovered in 1994-96. B) Hypothetical image of the EIA village of Cerro de San Vicente, based on archaeological investigations.

\subsection{Excavación en área de 2006}

Hasta 2005 las intervenciones en el yacimiento habían ofrecido una lectura vertical puntual en el sondeo de 1990, y habían exhumado en 2000-2001 los retazos de estratificación protohistórica entre las cimentaciones del cenobio de San Vicente. Pero tales restos no eran visitables: los de 1990 volvieron a cubrirse; los de 2001 quedaron intercalados entre el nuevo edificio museográfico. Por ello, en 2005 se planteó abrir en extensión un sector bien conservado -no afectado por los edificios históricos-, que ofreciera una imagen horizontal del poblado, con idea de su cubrición y exhibición pública permanente. La campaña de 2005-2006 se centró en la zona alta del teso, entonces ya protegida contra todo tipo de remoción y donde sólo pueden realizarse investigaciones arqueológicas. Se eligió la planicie cercana al flanco noreste, en el solar que había quedado bajo la pista deportiva de hormigón de la residencia universitaria que acababa de ser demolida. La cata cuadrangular planteada permitió comprobar que los niveles protohistóricos habían quedado perfectamente preservados bajo esa cancha deportiva. Se registraron cinco fases protohistóricas que corresponden a las últimas ocupaciones de la aldea (Alario García, 2007). Se exhumaron en área abierta unos $600 \mathrm{~m}^{2}$ del techo de la secuencia (fase III), descubriéndose cinco viviendas completas, otra parcial y 13 estructuras subsidiarias más pequeñas, todas ellas a ambos lados de un vial de tránsito parcialmente cubierto por cenizales (Figs. 1C y 8). Las construcciones del sector meridional (casas 5 y 6) fueron protegidas con geotextil y enterradas tras

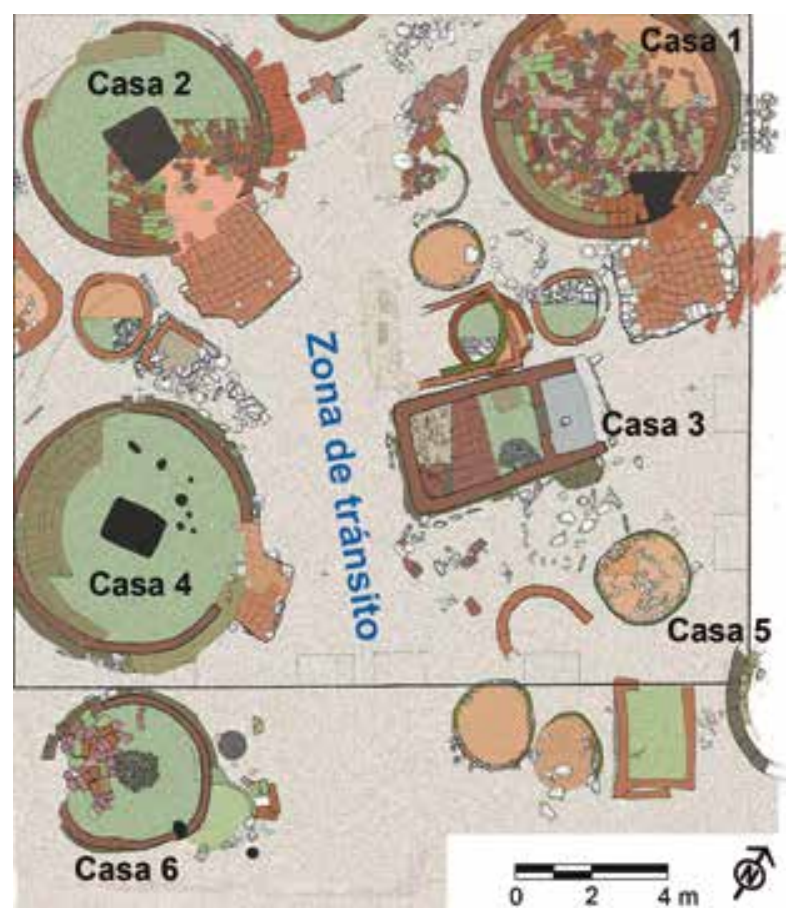

Fig. 8. Planta de la excavación en área abierta de 2006, con las viviendas y estructuras anexas de la fase III. / Plan of the open-area excavation in 2006, showing the houses and ancillary constructions belonging to phase III. 
la intervención, mientras que en los $400 \mathrm{~m}^{2}$ restantes, las casas 1, 2, 3 y 4 se consolidaron para su exhibición permanente dentro de una estructura cubierta (Fig. 2C).

Esta cata confirmó la preferencia cultural de los habitantes de CSV por las viviendas de barro de planta circular. En la fase III se han encontrado restos constructivos de manteados de barro aplicado, tal como se venían revistiendo las cabañas en los milenios anteriores (Ruiz Zapatero, 2007; Delibes de Castro y Romero Carnicero, 2011), pero la técnica más característica es el adobe (Fig. 9), cuyo uso se había constatado en CSV desde los niveles fundacionales excavados en el claustro conventual (Fig. 6A). Las viviendas cuentan con hogares de barro centrales y bancos adosados al muro opuesto a la entrada, esquema compartido por otras comunidades coetáneas de la cuenca del Duero (Romero Carnicero et al., 2008: 661-664; Ruiz Zapatero, 2009: 234-236; Arnáiz Alonso, 2017; Blanco García, 2017). Las cinco viviendas circulares detectadas (casas 1, 2, 4, 5 y 6) se construyeron con barro y presentan una serie de soluciones técnicas ya conocidas y algunas peculiaridades. Entre las primeras están los zócalos de adobe, atestiguados en Soto de Medinilla (Palol y Wattenberg, 1974: 187), Los Cuestos de la Estación (Benavente, Zamora) (Celis Sáchez, 1993: 107108, fig. 9) o Ledesma (Salamanca) (Benet Jordana et al., 1991: 126). También se habían documentado en otros lugares los vestíbulos de entrada trapezoidales, como en las casas 2 y 3 de Soto de Medinilla (Palol y Wattenberg, 1974: 190) y parcialmente en La Mota
(Medina del Campo, Valladolid) (Seco Villar y Treceño Losada, 1993: 134-144) o Los Cuestos de la Estación (Celis Sánchez, 1993: 102-114). Por el contrario, son distintivas del enclave salmantino los aceras perimetrales de adobe, en leve pendiente para facilitar la evacuación del agua de lluvia. Esta campaña permitió además comprobar que las viviendas circulares de la fase III o más reciente aparecían colmatadas de adobes en hiladas concéntricas, colocados en capas perfectamente horizontales, muy bien distinguibles en la casa 1 (Fig. 9). Tal solución no es habitual en el ámbito cultural soteño, si bien se documentó en Soto de Medinilla (Palol y Wattenberg, 1974: 187-191). No está claro cómo se formaron ni para qué sirvieron tales cúmulos de adobes. Las hiladas más cercanas a las paredes parecen colocadas, con los adobes acomodados uno a uno. Pero también hay amasijos de adobe desecho y parches amorfos que rellenan huecos, por lo que no puede descartarse la presencia de paredes desplomadas. Tales capas de adobe sirvieron de base para pavimentos de lechadas de arcilla dispuestos sobre ellas, como se observa en el último suelo de la casa 2 (Fig. 10). No sabemos si cada capa de recrecido del suelo corresponde a una reforma de la vivienda, repetida en varias ocasiones, o si pudiera tratarse de un único episodio de amortización del interior, inutilizando el suelo y el banco originales, como en la casa 1 (Fig. 9).

El edificio rectangular denominado casa 3 (Fig. 11) merece algunos comentarios. Esta construcción tiene tabiques internos y suelos a distintas alturas, y tan sólo

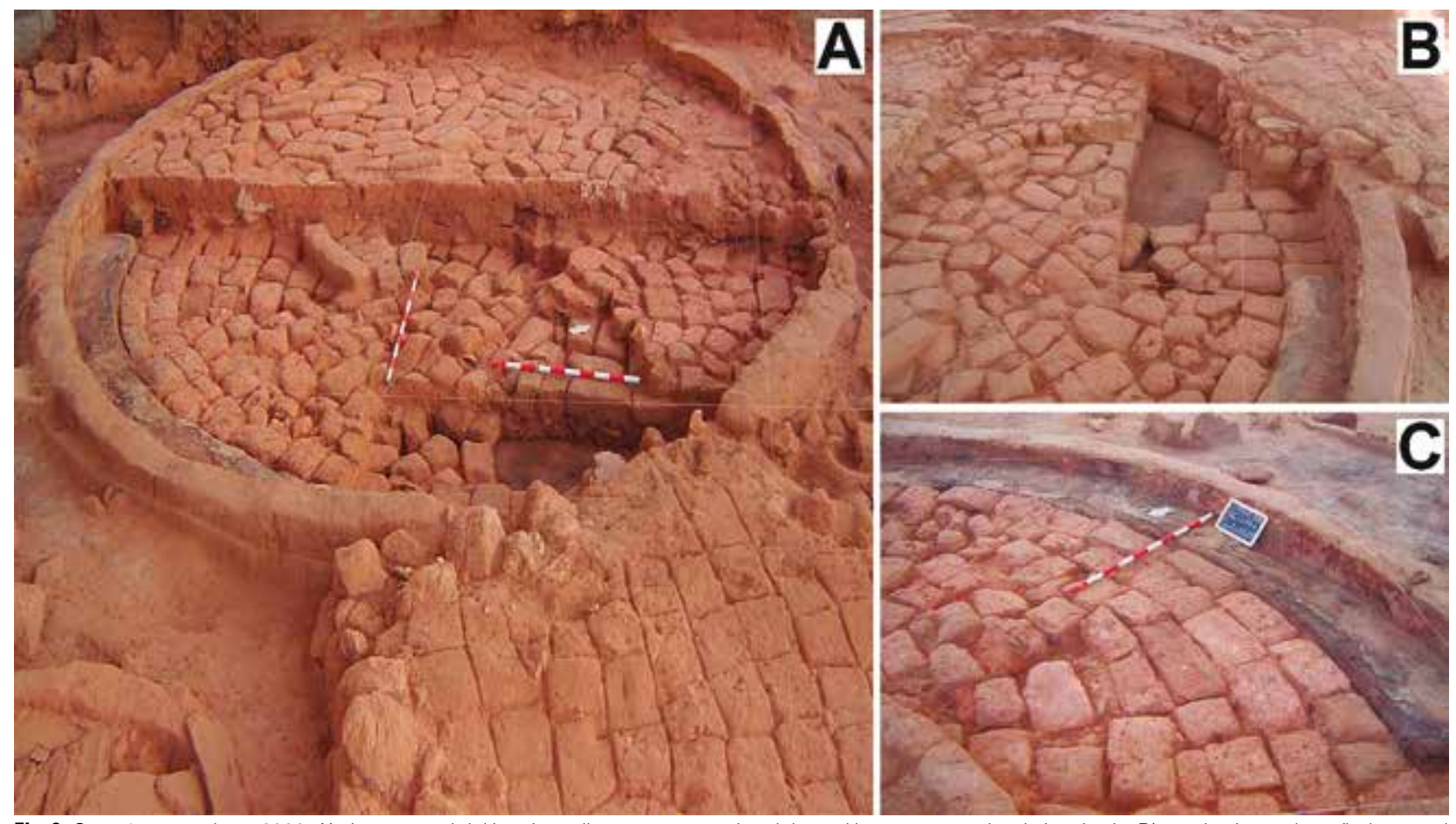

Fig. 9. Casa 1 excavada en 2006: A) vista general del interior, relleno con capas de adobe y el banco quemado a la izquierda; B) sondeo junto al vestíbulo, con el suelo quemado bajo los adobes; C) adobes colocados amortizando el banco. / Roundhouse 1 during excavations in 2006: A) mud-brick layers filling the interior and burnt bench to the left; B) pit by the entrance and porch showing the burnt floor under the adobes; C) mud-bricks sealing the bench. 


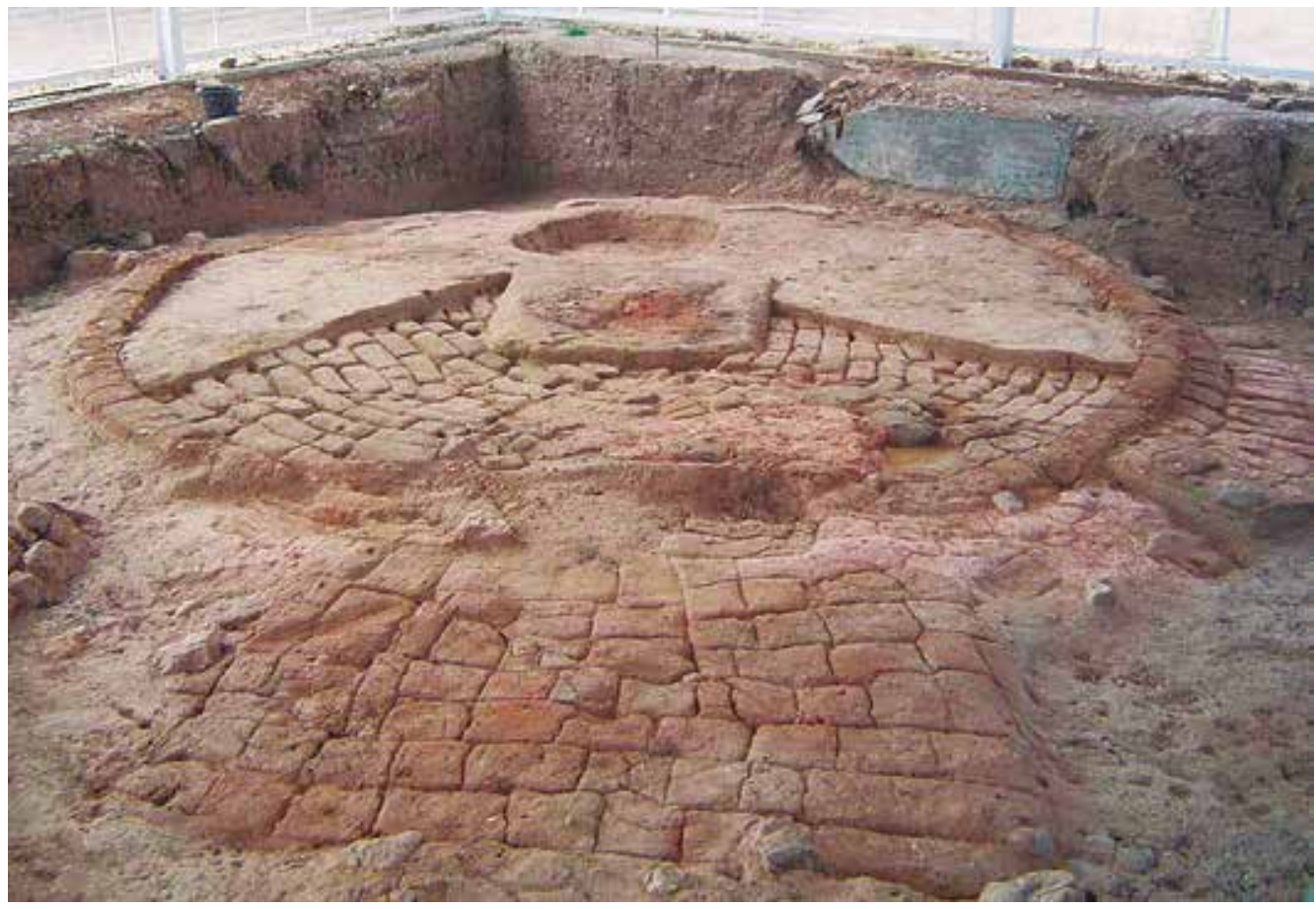

Fig.10. Casa 2 excavada en 2006. Sobre la capa de ado bes se dispuso una lechada arcillosa. Roundhouse 2 excavated in 2006, showing a mud soil over the mudbrick layer.

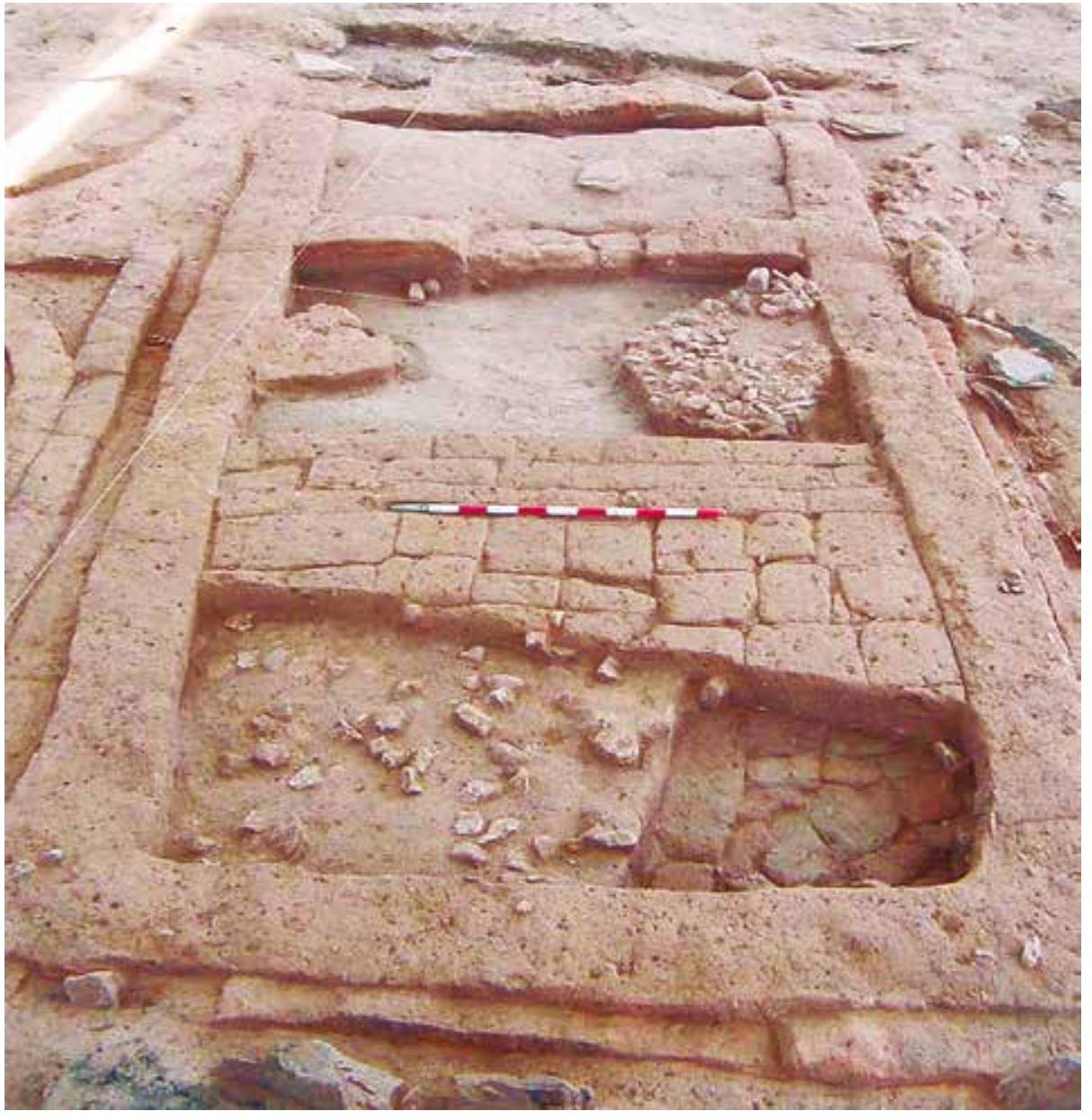

Fig.11. Casa 3 excavada en 2006. / Rectilinear house 3 , excavated in 2006 
se hallaron en su interior una afiladera, una moledera y una de laja de pizarra perforada (posible contrapeso de telar). No está claro su uso, y no podemos descartar funciones distintas a la estrictamente residencial. Pero, sobre todo, sus muros rectilíneos sin juntas de argamasa visibles -habituales entre los adobes- parecen levantados enteramente en bloques sólidos de barro. Así pues, además de los tradicionales embadurnados de barro y el novedoso uso de adobe, pudiéramos estar ante un ejemplo de arquitectura de tapial. En la literatura arqueológica peninsular hay una gran ambigüedad en la descripción de las técnicas constructivas de barro, y en CSV apenas podemos precisar cómo se realizaron paramentos como los de la casa 3. Pudiera tratarse de verdadero tapial (rammed earth o pisé de terre), es decir, muros levantados mediante tongadas de barro encofradas y apisonadas entre tablones de madera. Pero tales muros rectilíneos también pudieran haberse realizado apelmazando a mano, sin encofrar, grandes pellas de barro (bauge o façonnage direct) (Belarte, 2002: 40-41). En cualquier caso, se trata de técnicas constructivas sin precedentes locales, pues antes del primer milenio AC no hay testimonios indiscutibles de arquitectura de barro masiva - es decir, estructural, y no sólo para impermeabilizar- en la Meseta (Romero Carnicero, 1992; Álvarez-Sanchís, 1999, 2003; Romero Carnicero et al., 2008; Arnáiz Alonso, 2017). Gran parte de la historiografía admite que los fenicios trajeron tales técnicas edilicias a la península Ibérica y que pudieron expandirse desde sus asentamientos costeros hacia el interior (Díes Cusí, 2001; Belarte, 2002). Algunos autores cuestionan tal posibilidad y defienden su presencia precolonial (Vives-Ferrándiz, 2006), de momento pobremente argumentada.

Las casas muestran capas de arcilla extendidas por el suelo, hogar, poyos y muros y no depararon restos de enseres ni mobiliario in situ, más allá de posibles vasares o peanas. Las viviendas se mantuvieron limpias de desechos, como suele ser habitual (LaMotta y Schiffer, 1999; Jiménez Jáimez, 2008) y los desperdicios se trasladaban fuera del edificio. En ocasiones se han reconocido niveles de incendio en el interior de las viviendas que sugieren intensos fuegos, como en la casa 1 (Fig. 9). Muchos de sus adobes aparecen rubefactados, incluso con algunas caras ennegrecidas, por lo que el incendio del interior de esta vivienda parece muy plausible, tras lo cual se desmontaron las paredes y su interior se amortizó con adobes. El techado de estas estancias es desconocido. Dentro de algunas casas se han reconocido pies de postes con calzos de piedra, así como restos de vigas carbonizadas y, como se ha dicho, son frecuentes los fragmentos de manteado de barro con improntas de entramado de madera que podrían haber pertenecido a cubiertas vegetales.

Entre las casas se disponen las estructuras anejas, de menor tamaño $\left(<7 \mathrm{~m}^{2}\right)$ y planta circular o rectangular, en ocasiones superpuestas (Fig. 11A) como ocurre con las viviendas. Su sedimento de relleno resulta inexpresivo, dificultando así su interpretación funcional. Una de estas construcciones procuró abundantes granos de cebada carbonizados, lo que indica su uso como granero o troje. Esta interpretación es coherente con el cuidado puesto en preparar los suelos, mediante una sucesión de capas que proporcionaban superficies lisas y resistentes y garantizaban su impermeabilidad. Así, sobre un encachado de lajas de pizarra se disponía una capa de gravilla y margas y todo ello se recubría con un solado amorterado de arenisca machacada mezclada con agua y arena (Fig. 12B). Esta técnica de fraguado empleando materiales locales forma una masa muy resistente. Su uso perduró hasta época medieval.
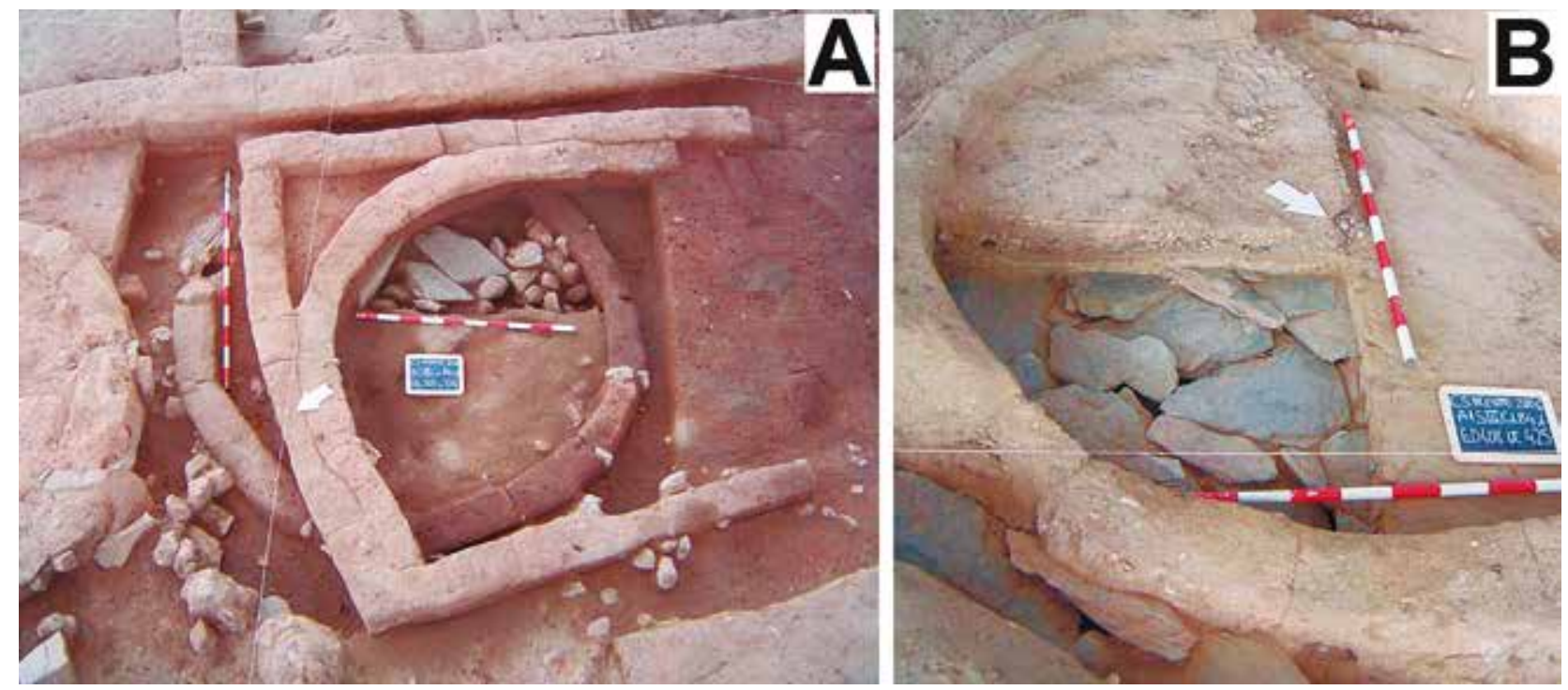

Fig.12. A) Superposición de estructuras subsidiarias en la cata de 2006. B) Microestratigrafía del corte practicado al suelo de una de ellas. / A) Superimposed auxiliary devices excavated in 2006. B) Microstratigraphy of the floor of one of these structures. 
Respecto al repertorio material, se han encontrado objetos óseos (punzones, mangos), de hierro (fragmentos indeterminados y hojas de cuchillos) y bronce (fíbulas de doble resorte, apliques, leznas); abundantes subproductos metalúrgicos (goterones, escorias) y utensilios metalúrgicos (crisoles) relacionados con el cobre y numerosos molinos barquiformes de granito. Pero es la cerámica el material más abundante, predominando la vajilla a mano, acompañada de las primeras importaciones torneadas en los niveles superiores. Entre la alcallería manufacturada hay grandes orzas de almacenaje y ollas de cocina. La vajilla de mesa ofrece vasos de perfil bitroncocónico, cuencos, platos, tapaderas y recipientes globulares, a menudo con mamelones perforados y un intenso bruñido. Los fondos suelen ser planos, pero los recipientes finos portan bases um- sa a peine (sogueados, flores) e incisiones (retículas) (Fig. 4) inaugurando una producción alfarera con un gran desarrollo en el Hierro II (Álvarez-Sanchís, 1999, 2003, 2010). Sin embargo, las fechas proporcionadas por los fósiles-directores deben aún ser comprobadas con rigor; la tipología tiende a ofrecer estimaciones más recientes que las obtenidas con métodos científico-naturales (Hamilton et al., 2015).

Un objeto reseñable por su rareza es un recipiente cerámico hecho a mano e intensamente bruñido (Fig. 14). Presenta un gollete central y dos protuberancias laterales, la menor de ellas hueca y ambas rotas, y en su base conserva el arranque cuatro apéndices, también fracturados. Esta vasija polípoda se encontró bocabajo en 2006 entre el escombro de un edificio rectangular exhumado parcialmente en una de las zapatas para an-

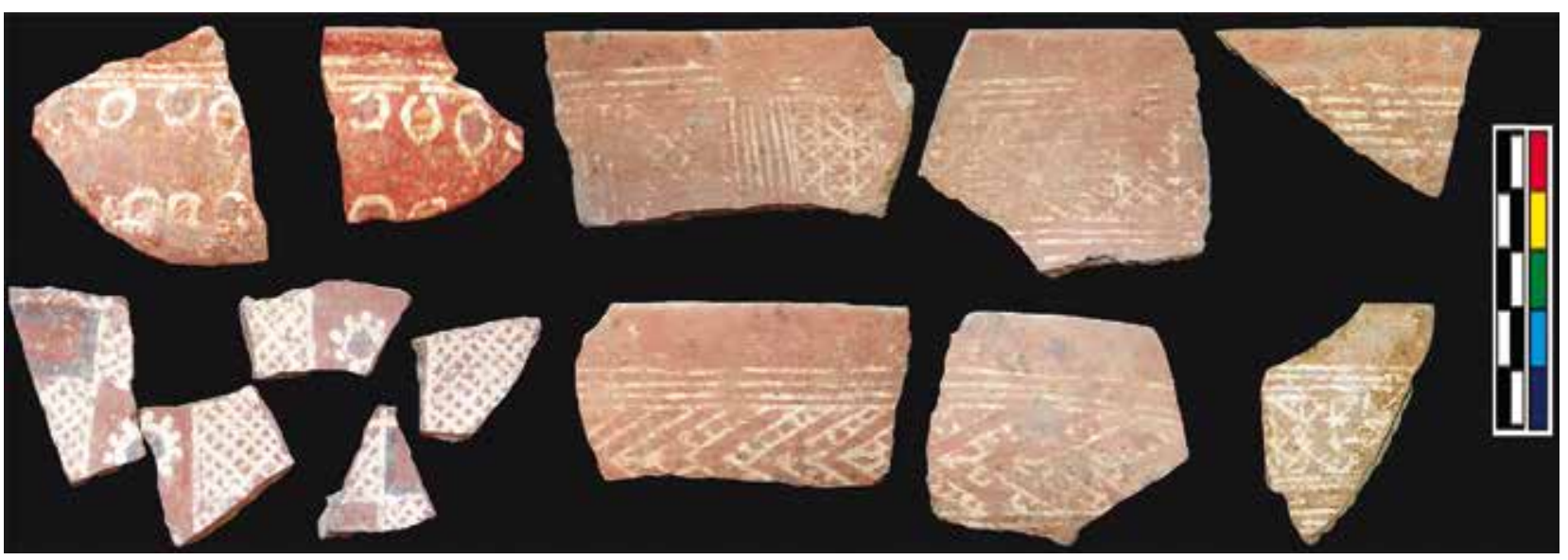

Fig.13. Vajilla a mano pintada poscocción. Escala en $\mathrm{cm}$. / Hand-made painted pottery. Scale in cm.

bilicadas y pies realzados, en ocasiones con molduras. Las decoraciones se limitan a las digitaciones, ungulaciones e impresiones de espátula en el labio. Algunos recipientes de consumo individual (cuencos, vasitos troncocónicos o de perfil sinuoso) recibieron grafito o pintura poscocción en ambas superficies; suele tratarse de motivos bícromos geométricos (aspas, retículas, círculos, zigzags, soliformes, etc.) en blanco, negro o azul sobre fondo rojo (Fig. 13). Estos motivos geométricos, así como las frecuentes incisiones de rombos con rallado interno propios de la cerámica común se relacionan con los primeros siglos del Primer Hierro meseteño (c. 800-600 AC), si bien hay perduraciones (Blasco Bosqued et al., 1991; Delibes de Castro et al., 1995b; Álvarez-Sanchís, 1999; Torres Rodríguez, 2013) y guardan gran similitud con la vajilla con decoración pintada geométrica de tipo Carambolo (Casado Ariza, 2015). Es también reseñable la presencia de decoración puntillada, que en un caso reproduce un antropomorfo con buenos paralelos en el valle medio del Tajo (Torres Rodríguez, 2013: 211, fig. 4.52). A partir de un momento impreciso, cuya fecha más antigua admitida es c. 650 a.C. (González-Tablas, 1990: 70-74), cuencos y vasitos comienzan a exhibir decoración impre-

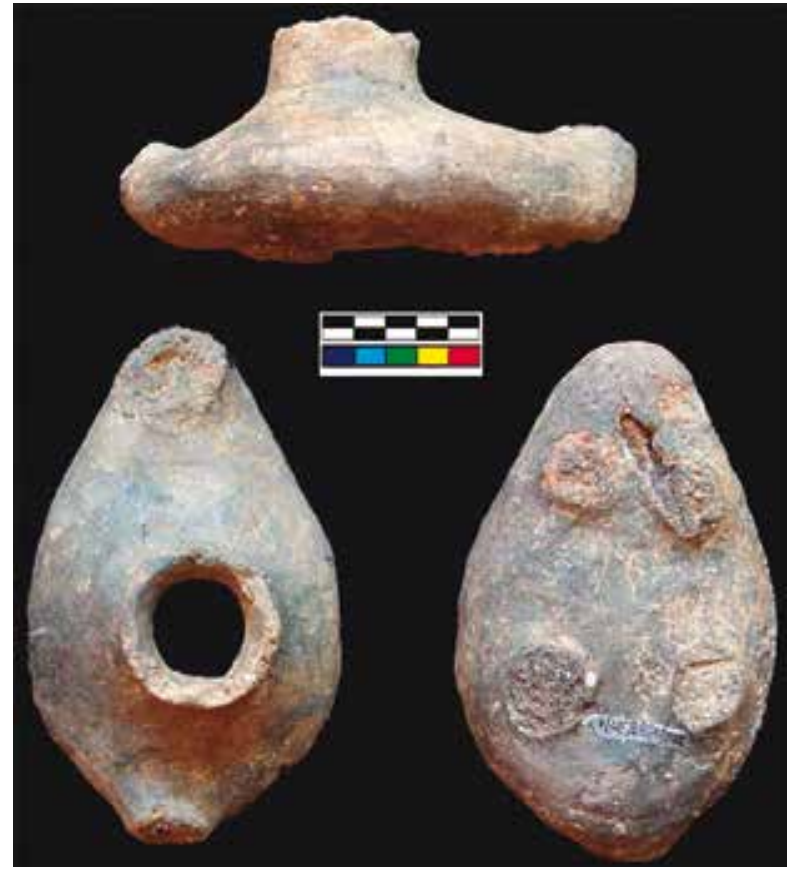

Fig.14. Recipiente de cerámica polípodo, de uso desconocido. Escala en $\mathrm{cm}$. / Rare zoomorphic terracotta object, with unknown function. Scale in cm. 
clar la cubierta metálica (UE 517, fase II). Inicialmente se propuso su interpretación como una lámpara o candil, pero no se parece a las lucernas torneadas fenicias y carece de huellas de hollín. Tal vez se utilizó como instrumento musical de tipo idiófono, o más probablemente fuera una vasija ritual para líquidos o perfumes. Si atendemos a su zoomorfismo -recuerda a un ave, aunque sería cuadrúpeda-, sus mejores paralelos se encuentran entre los vasitos ornitomorfos mediterráneos púnicos e ibéricos. El paralelo más próximo es un askos del siglo IV a.C. de la necrópolis de La Trasguija de Las Cogotas (Cardeñosa, Ávila) (Barril Vicente y Galán Domingo, 2007: 144-147) del que sería un lejano precedente.

Las tres dataciones de ${ }^{14} \mathrm{C}$ obtenidas en 2006 sitúan la fase III exhumada en área abierta entre los siglos VIII y VI cal AC (Tabla 1). Tales fechas confirman los valores extremos más antiguos de las dataciones obtenidas anteriormente, pero con un matiz no desdeñable (Macarro Alcalde y Alario García, 2002: 84, nota 26): hay un 89\% de probabilidades de que la muestra CSIC-2072, obtenida del nivel de incendio y abandono de la casa 1 - es decir, del final de la biografía de esta aldea- está comprendida entre 820-750 cal AC. Las otras dos estimaciones (CSIC-2126 y Ua-34086) son coherentes con la anterior, pero no añaden mayor precisión por la amplia incertidumbre de la 'meseta de Hallstatt'. A partir de criterios tipológicos, la cultura material y las formas constructivas halladas en 2006 cuadran bien con un contexto tardío del Primer Hierro, en torno al siglo VI a.C. Por su parte, el ${ }^{14} \mathrm{C}$ sitúa tales manifestaciones hacia 540 cal AC como valor más reciente, y durante los dos siglos previos con igual o mayor probabilidad. Es ineludible recurrir a técnicas de datación alternativas para resolver la situación cronológica del techo de la secuencia de este yacimiento.

\section{DISCUSIÓN}

\subsection{Arqueología doméstica, procesos formati- vos y prácticas sociales}

A partir de las distintas intervenciones practicadas hasta ahora, los restos arqueológicos del Cerro de San Vicente proceden mayoritariamente de dos escenarios deposicionales: a) cenizales o basureros al exterior de las viviendas; y b) el interior de edificios (casas, graneros, despensas, etc.). Ambos contextos son bien conocidos en la literatura sobre los asentamientos de la Primera Edad del Hierro meseteña (Blasco Bosqued et al., 1991; Delibes de Castro et al., 1995a; Romero Carnicero et al., 2008; Morín y Urbina, 2012; Torres Rodríguez, 2013). Sin embargo, apenas se han elaborado sus estrategias de excavación ni se ha reflexionado sobre su potencial informativo. A continuación examinare- mos con mayor detalle ambos tipos de acumulaciones a partir de lo encontrado en CSV, para diferenciar sus dinámicas y ritmos de formación y señalar aquellos aspectos sobre los que pueden informar mejor.

Por una parte tenemos los cenizales domésticos, próximos a las viviendas ${ }^{1}$, y compuestos de lentejones ricos en materia orgánica bien preservada (fauna consumida, cenizas y macrorrestos vegetales carbonizados de la lumbre del hogar) y otros desechos inorgánicos (cerámica y metales descartados). Estos muladares parecen responder a episodios habituales y reiterados de vertido de desperdicios domésticos por parte del grupo residente en la vivienda a la que se asocian espacialmente, aunque tal hipótesis no ha sido comprobada. De estar en lo cierto, resultan idóneos como fuente de información de la vida cotidiana de los segmentos o grupos corporativos dentro de la aldea (familia, clan, linaje) que los generaron. No obstante, son cúmulos de desperdicios parciales y selectivos: no está todo lo descartado, sino sólo algunos desechos culinarios (fauna), vajilla cerámica inservible y no reciclable, inmundicia de la limpieza periódica de los hogares, etc. También es necesario recalcar que se trata de restos extraídos de su 'contexto sistémico' o de uso (las viviendas) y redepositados (Schiffer, 1987). Es decir, que las relaciones espaciales originarias entre ítems han desaparecido y el vínculo entre cenizal y su respectiva vivienda o viviendas debe ser rastreado.

Por otra parte están las construcciones de barro. Su buena conservación a menudo ha animado la interpretación espacial y funcional (p.e. Delibes de Castro et al., 1995b; Celestino Pérez, 1996; Romero Carnicero et al. 2008; Rodríguez Díaz et al., 2009, 2015a; Arnáiz Alonso, 2017). En CSV esa circunstancia responde en gran medida a una voluntad premeditada (basada en la redundancia de usos y la acumulación material) antes que a un efecto azaroso. Así, las excavaciones en diferentes puntos del teso han confirmado la persistencia diacrónica en los usos del espacio: las casas se superponen a otras previas, los espacios abiertos perduraron en sucesivas fases y los cenizales continuaron apilándose durante décadas. Ese principio de redundancia y acumulación también estuvo vigente en las viviendas: las entradas de algunas casas se orientaron exactamente como lo hicieron las infrayacentes - normalmente hacia el sureste - y los hogares centrales coinciden con los de casas previas. Una pauta similar se constata en los sucesivos altares de Cancho Roano (Celestino Pérez, 2001: figs. 21 y 26). En el mismo sentido, los cimientos de las casas se respetaron y preservaron como fundamento (físico y simbólico) de las nuevas casas. Estas observaciones sugieren que ciertos episodios de renovación de la vivienda pudieron ser relevantes, y conllevaron prácticas imbuidas de simbolismo. Así, al sustituir el antiguo enlucido bicolor de la casa 6 exca-

1 A menudo los cenizales incluso cubrieron parcialmente los muros de las viviendas, procurando cierto aislamiento contra la humedad. 
vada en 1990 por una nueva capa rojiza, sus habitantes depositaron algunas porciones desmontadas dentro de un hoyo en su entrada (Fig. 3B). En la campaña de 2002 en el claustro conventual se encontró un neonato en una fosa (UE 72-73) bajo el pavimento de una vivienda de la fase II. Esta práctica estuvo extendida por entonces (Romero Carnicero et al., 2008; Sánchez Alonso, 2015) y acaso pudiera indicar cierta relación entre tales óbitos y la refundación simbólica del hogar.

En todo caso, el hecho de que cimientos y paramentos de las casas sigan en posición primaria no implica que su contenido interno haya compartido esa afortunada circunstancia. Es crucial distinguir si los restos encontrados fueron ofrendas, objetos en desuso abandonados, o residuos erráticos de ocupaciones previas. Sólo un examen crítico atento a cómo acabaron allí materiales y sedimentos nos permitirá discriminar entre una amplia gama de matices no intuitivos ni evidentes. En CSV los interiores de las viviendas contienen detritos constructivos y desechos domésticos, pero su génesis no es fácil de discernir. Por lo observado durante la excavación (sin haber desarrollado un examen exhaustivo posterior), apenas hay objetos completos rotos in situ, que pudiéramos considerar desechos de facto, es decir, usados y dejados en dichas estancias al clausurarlas (Schiffer, 1987; LaMotta y Schiffer, 1999). En otros asentamientos del Primer Hierro sí es lícito pensar en objetos abandonados o colocados antes de la deserción de la estancia, como la docena de vasijas completas del nivel de incendio de la vivienda $\mathrm{n}^{\circ} 1$ de La Mota (Medina del Campo, Valladolid) (Seco Villar y Treceño Losada, 1993: 137 y 157). En CSV las viviendas y estructuras anejas parecen haber sido despojadas de los enseres y mobiliario esperable en tales contextos. Así pues, por ahora la 'premisa pompeyana' (Jiménez Jáimez, 2008; Ruiz Zapatero, 2013: 47-48) no es aplicable aquí. Esta constatación es importante porque nos previene contra cualquier interpretación directa y sencilla en términos utilitarios, funcionales o de organización social del espacio.

Respecto al material constructivo dentro de las viviendas (fundamentalmente adobes y escombro de barro), ya hemos señalado que algunas casas circulares parecen haber sido selladas concienzudamente, pero se trata de una idea aún por esclarecer. También hemos de aclarar a qué responden las frecuentes huellas de fuegos intensos: suelos, paredes y adobes rubefactados y niveles de combustión sobre pavimentos (Fig. 6). De haber sido intencionados (es decir, prendidos y alimentados con combustible) podrían haber sido parte del procedimiento de abandono, como en otros asentamientos prehistóricos europeos de tipo tell (cf. Stevanović, 1997). Tampoco está claro si las casas contienen desplomes de cubiertas y paramentos. Existe la posibilidad de que, tras el incendio de la vivienda, sus techos y paredes fueran desmantelados, procurando así los adobes que finalmente se emplearon para colmatar su interior.
En suma, de no estar equivocados, las acumulaciones de restos domésticos aquí estudiadas podrían estar informándonos de episodios ocasionales de construcción, reforma y abandono. Es decir, que serían resultado de acciones esporádicas, repetidas cada cierto tiempo, y por tanto, serían una fuente válida para indagar sobre esos hábitos no cotidianos que jalonaron las biografías de las aldeas.

\subsection{Sociedad y economía del Primer Hierro en el sector occidental de la cuenca del Duero}

Las excavaciones presentadas aquí también pueden contribuir a un mejor conocimiento de los modos de vida y la organización social de las aldeas del Primer Hierro meseteño. Prestaremos particular atención a las ocupaciones más recientes de CSV exhumadas durante las campañas de 1990 y 2006.

Los estudios disponibles sobre paleoeconomía y paleoambiente en el Primer Hierro de la cuenca del Duero se han centrado preferentemente en las campiñas y páramos vallisoletanos (Delibes de Castro et al., 1995a; Romero Carnicero y Cubero Corpas, 1999). En CSV se han llevado a cabo análisis carpológicos, polínicos y zooarqueológicos, aún por publicar de forma extensa (Macarro Alcalde y Alario García, 2002), que informan sobre tales aspectos en el occidente meseteño y complementan lo conocido en el valle medio del Duero. La subsistencia está estrechamente vinculada con la organización interna de esta aldea y su trayectoria social. El inicio de la Edad del Hierro en el valle del Duero (c. 900 cal AC), como en gran parte del cuadrante noroeste ibérico, se caracteriza por agregaciones de familias en comunidades agrarias autosuficientes: las aldeas. Tales comunidades aldeanas estuvieron compuestas de grupos corporativos (linajes o clanes) que convivieron bajo un apariencia isonómica o igualitarista, cuyo mejor exponente del esfuerzo colectivo es la muralla (e.g., González-Ruibal, 2006-7: 194; González García et al., 2011). La homogeneidad de su arquitectura y la ausencia de diferencias en los inventarios domésticos o en el acceso a bienes y recursos (Romero Carnicero et al., 2008: 676; Torres Rodríguez, 2013: 251-257) se compadecen bien con unas sociedades agrarias segmentarias de tipo campesino, sin desequilibrios internos y con una fuerte ideología comunitaria. Tales grupos aldeanos basaron su subsistencia en la diversificación productiva y en la inexistencia de excedente más allá de las necesidades agrarias y sociales (Esparza Arroyo, 1995, 2011; Parcero Oubiña, 2002; Fernández-Posse y Sánchez-Palencia, 1998; Sastre et al., 2010; Ruiz-Zapatero y Álvarez-Sanchís, 2015). Tal modelo aldeano pudo funcionar en el sector occidental del Duero desde c. 900-800 cal AC, es decir, en momentos tan tempranos (o incluso más) como en el Duero medio, como se ha sugerido para el nivel fundacional de Los Cuestos de la Estación (Esparza et al., 2016). La fundación de la aldea de CSV carece de una data- 
ción precisa, pero una antigüedad similar no resultaría extraña.

Las ocupaciones del techo de la secuencia de CSV pueden situarse en un rango temporal amplio y de límites imprecisos (c. 750-500 cal AC), que corresponden a un estadio avanzado y distintivo de ese proceso histórico. Al final de la biografía aldeana de CSV las distintas informaciones disponibles indican la práctica de estrategias agrarias integradas y complejas, de arado ligero, con cierta intensificación productiva y rendimientos crecientes (Ruiz-Gálvez, 1992, 1998). Así, en este sector del Duero se desarrolló una agricultura de barbecho corto (anual o bianual) basada en el trigo (Triticum aestivum/durum y Triticum dicoccum) combinado con otros cereales minoritarios, como la cebada (Hordeum vulgare) y legumbres (Vicia faba), tal como se ha apuntado en el Duero medio (Romero Carnicero y Cubero Corpas, 1999; Romero Carnicero et al., 2008: 664-668). El muestreo palinológico en CSV indica una cobertera de bosque de ribera densa y estable. El paulatino descenso de las masas forestales y la extensión del matorral sitúan el máximo impacto de las actividades agropastoriles durante las últimas ocupaciones. Por su parte, la colección faunística de la fase III obtenida en 2006 informa sobre las pautas de consumo (Macarro Alcalde y Alario García, 2002: 79-82). Se aprecian marcas de carnicería con cuchillos metálicos y un $80 \%$ de los animales consumidos son domésticos, mayoritariamente oveja (Ovis aries), seguido de cerdo (Sus sp.) y vaca/buey (Bos taurus), estos últimos empleados como animales de tiro, según indican patologías óseas bien conocidas en lugares coetáneos (Romero Carnicero y Cubero Corpas, 1999: 179).

A partir de lo conocido, en su etapa final la aldea de CSV pudo acoger unos 60 grupos parentelares, es decir unos 250 vecinos -asumiendo cuatro miembros por familia- en sintonía con cálculos similares (González-Ruibal, 2006-7: 205-206). Así pues, fueron concentraciones notables de vecinos, donde las tensiones podrían aflorar con facilidad. Frente a las aldeas de comienzos del Hierro, menos populosas, espacialmente desagregadas e igualitarias (Romero Carnicero et al., 2008; Blanco García, 2017: 662), entonces la vivienda adquiere una importancia inusitada, al tiempo que la anatomía de la aldea se compartimenta. Ya se había observado que las casas circulares de las últimas ocupaciones en el Soto de Medinilla añaden vestíbulos o atrios, su interior se elabora y decora más y presenta grandes orzas de almacenaje del grupo residente (Romero Carnicero y Cubero Corpas, 1999: 183-184; Romero Carnicero et al., 2008: 680). Un proceso similar se atisba en CSV, cuyas casas de la fase III presentan esmerados enlucidos polícromos, atrios y patios pavimentados con adobe, e incluso se dotan de desagües (Fig. 3B). Se ha sugerido que los motivos pintados en vasijas y viviendas pudieran haber funcionado como emblemas de tales facciones (Macarro Alcalde, 2014: 48). Ese énfasis material en el ámbito doméstico coincidió con la demarcación arquitectónica de cada segmento familiar dentro de la aldea. Tanto en La Corona/El Pesadero (Misiego Tejeda et al., 2013: 190-206) como en CSV los grupos residentes deslindan su vivienda y construcciones subsidiarias de las de los vecinos. Surgen así los agregados de viviendas y construcciones adjetivas funcionalmente complementarias al servicio de un mismo grupo residente (Romero Carnicero et al., 2008: 664). En el caso de CSV, sabemos que tales agrupaciones constructivas emplearon alineaciones de piedra, como la documentada en 1990 (Fig. 3B). Dichos vecindarios son comparables con arquitecturas tardías del Hierro II, caso de las 'unidades de ocupación' de los castros leoneses (Fernández-Posse y Sánchez-Palencia, 1998: 130), los 'conjuntos de habitación' de las casas-patio en los oppida bracarenses (González-Ruibal, 2006-7: 410-419; 2009), u otros complejos arquitectónicos similares entre los oppida vacceos del Duero medio (Heredero García, 1993: 290).

En definitiva, en el techo de la secuencia de CSV proliferaron las casas circulares con atrio en cuyo ornato y mantenimiento se invirtió decididamente. Esas viviendas se integraron además en complejos de construcciones funcionalmente autónomos y separados físicamente entre sí por cercas o viales. Tales transformaciones arquitectónicas, reconocidas en otras aldeas del occidente del Duero, sugieren cambios importantes en las relaciones sociales y productivas entre familias, aspecto este aún no suficientemente evaluado en ningún yacimiento meseteño. Una serie de factores históricos concurrieron en tal coyuntura: cierta intensificación agraria y producción de excedente, una demografía alcista, y cambios en el régimen de tenencia de tierras y ganados (Ruiz-Gálvez, 1998; Romero Carnicero et al., 2008: 680). Pese a reconocere ampliamente la contribución de tales vectores, no está clara su relación en términos de causa y efecto.

Como hipótesis de trabajo, las observaciones arqueológicas previas podrían entenderse mejor en un clima de quiebra de la solidaridad campesina de comienzos del proceso, ante el impacto de fuerzas centrífugas largo tiempo contenidas. Así, poco antes de su abandono, tales aldeas habrían experimentado una creciente jerarquización y competencia interfamiliar basada en la apropiación de la riqueza agraria. Los protagonistas de tal deriva habrían sido los grupos corporativos familiares (linajes o clanes), que actuaron como unidades socio-económicas autónomas y perpetuadas para acumular, exhibir y transmitir su patrimonio y prestigio social (Parcero Oubiña, 2002; González-Ruibal, 2009). Sus miembros, vinculados por parentesco biológico o cultural (respecto a un antepasado común, real o mítico), habrían tenido en las 'unidades domésticas' y en las casas circulares con atrio un referente físico y simbólico de primer orden. Esta imagen se compadece bien con unas comunidades heterárquicas inestables, con linajes dentro de las aldeas compitiendo entre sí (Ruiz Zapatero, 2009; López Jiménez, 2011; Torres Rodríguez, 2013: 257-261; Rodríguez Díaz et al., 2015b; Ruiz Zapatero y Álvarez-Sanchís, 2015; Arnáiz Alonso, 
2017). Tal esquema podría cuadrar con el modelo sociológico del 'modo de producción germánico' (Gilman, 1995; Parcero Oubiña, 2002: 179-182). Además, ciertos elementos materiales (la inversión en la vivienda, la superposición estructural, la redundancia de usos, las inhumaciones infantiles, la presencia de reliquias, etc.) están próximos al modelo marcadamente desigualitario de la 'sociedad de casa' (stem family-house society) (González-Ruibal y Ruiz-Gálvez, 2016).

\section{CONCLUSIONES}

Este artículo ha presentado de forma sintética algunas observaciones efectuadas durante las últimas décadas de excavaciones en el asentamiento del Cerro de San Vicente. Se han señalado tanto los aspectos mejor conocidos como las numerosas cuestiones irresueltas que aún deben ser aclaradas. Su examen crítico permite ofrecer nueva luz y formular nuevas preguntas sobre cuestiones importantes, pero que apenas han sido discutidas en la arqueología del primer milenio AC de la península Ibérica.

Frente a la extendida 'premisa pompeyana' (Jiménez Jáimez, 2008), que asume que la arqueología doméstica de la Edad del Hierro es sencilla y no problemática, una mirada atenta a los procesos formativos nos ha permitido atisbar la complejidad de su génesis. La ausencia de edificios que claramente se hayan desmoronado de manera súbita, atrapando los repertorios domésticos en uso, plantea un reto a la investigación de la vida cotidiana en la protohistoria. Aquí se ha sugerido que los habituales cenizales o basureros pueden servir como fuente para estudiar esa cotidianeidad. Sin embargo, se han señalado algunos de los problemas que presenta tal fuente de información. En particular, en el futuro deberán elaborarse estrategias para vincular viviendas y basureros familiares. También se ha enfatizado que la redundancia y acumulación material (de suelos, enlucidos parietales, cimientos, hogares, cenizales, etc.) fueron principios seguidos por los habitantes de esta aldea en muy diversas situaciones: desde las costumbres cotidianas a las ocasiones especiales de reforma o refundación de una vivienda.

Este tipo de yacimientos pudieran pues comprenderse como el efecto no buscado de mucha gente desechando su basura junto a las casas, así como construyendo y reconstruyendo sus edificios sobre los anteriores. Tales decisiones culturales son coherentes con la intención de permanencia indefinida que caracteriza a estas comunidades (Romero Carnicero et al., 2008; Delibes de Castro y Romero Carnicero, 2011; Esparza Arroyo, 2011; Torres Rodríguez, 2013; Ruiz Zapatero y Álvarez-Sanchís, 2015). Así pues, se trata de una arqueología muy mediatizada por ese tipo de normas de comportamiento, que, en el caso de las viviendas, probablemente buscaba reforzar la identidad corporativa de los linajes y entroncar su genealogía con los antepasados.
La discusión previa abre la puerta a entrever la presencia a finales del Primer Hierro meseteño de formas de organización social heterárquicas basadas en la propiedad agraria y su transmisión desigual. Por el marcado papel desempeñado por las viviendas como sede elemental de la sociabilidad, se trató de comunidades centradas en la casa (house-centric societies) (González-Ruibal y Ruiz-Gálvez, 2016: 390). Ello contrasta con el modelo transigualitario propuesto en la cuenca del Tajo para un estadio avanzado el Primer Hierro (Torres Rodríguez, 2013), más inestable y efímero. Así, habría que pensar en un clima inestable de alta conflictividad social entre un amplio estrato social de grupos parentelares. A la postre tales linajes fracasaron en su intento de monopolizar el poder y c. 400 AC dieron paso a nuevas formas de organizar la sociedad.

Quedan muchos aspectos por aclarar, pero las hipótesis aquí esbozadas podrán abrir nuevas líneas de pesquisa. Es prioritario caracterizar mejor las estrategias de subsistencia de esos grupos aldeanos, y aquilatar los principales hitos de sus trayectorias diacrónicas. Para ello es imprescindible conseguir una cronología mucho más precisa que la manejada habitualmente por la investigación sobre el primer milenio AC. El hecho de que las viviendas no contengan los enseres domésticos debe servir de acicate para idear estrategias imaginativas y eficaces para evaluar las posibles disimetrías en la capacidad de almacenaje y consumo entre distintas unidades domésticas. La huella material del desigual éxito de unos linajes frente a sus vecinos sería visible en aspectos clave como: a) la ampliación de su parentela (descendencia como fuerza de trabajo y capital social); b) el acopio y la transmisión hereditaria de su patrimonio físico (la vivienda, los aperos y enseres, tierras y ganado) y simbólico (prácticas ritualizadas, emblemas familiares). Futuras campañas de excavación en el Cerro de San Vicente abordarán algunas de tales cuestiones desde protocolos de investigación multidisciplinar. Esperamos contribuir con ello a una comprensión más fina y matizada de la arqueología de los comienzos de la Edad del Hierro en el interior peninsular.

\section{AGRADECIMIENTOS}

Recibimos ayuda y sugerencias de D. Juan José Padilla Fernández, del Prof. Richard Dumbrill, Dr. Sarah Barber y Dr. Guy David Hepp sobre la interpretación del vasito polípodo hallado en 2006. El trabajo de campo recibió financiación de promotores privados, el Fondo Social Europeo, la Junta de Castilla y León y el Ayuntamiento de Salamanca (http://www.salamanca. es/cerro/ ; https://cerrodesanvicente.wordpress.com/)

\section{BIBLIOGRAFIA}

Alario García, C., 2008. Informe Técnico Arqueológico. Excavación Arqueológica en el Cerro de San Vicente, Salamanca. Campaña 2005-2007. $3^{\text {a }}$ Fase de las Obras de Protección de 
los restos de la Planta del Antiguo Convento de San Vicente. Documento inédito. Dirección General de Patrimonio Cultural de la Junta de Castilla y León.

Alario García, C., Macarro Alcalde, C., 2007. La ciudad Hispanorromana de Salmantica a partir de la secuencia estratigráfica del Solar del Trilingue. In: Gianini, G., Santonja, M. (Eds), Arqueología de la Vía de la Plata (Salamanca), 213-242. Premysa, Béjar.

Álvarez-Sanchís, J.R., 1999. Los Vettones. Real Academia de la Historia, Madrid.

Álvarez-Sanchís, J.R., 2003. Los señores del ganado. Arqueología de los pueblos prerromanos en el occidente de Iberia. Akal, Madrid.

Álvarez-Sanchís, J.R., 2010. La cerámica con decoración a peine, de 'fósil guía' a indicador de etnicidad. In: Romero Carnicero, F., Sanz Mínguez, C. (Eds.), De la región vaccea a la arqueología vaccea, 293-318. Universidad de Valladolid, Valladolid.

Álvarez-Sanchís, J.R., Jimeno Martínez, A., Ruiz Zapatero, G., (Eds.), 2011. Aldeas y ciudades en el primer milenio a.C. La Meseta Norte y los orígenes del urbanismo. Complutum 22(2). Universidad Complutente de Madrid, Madrid.

Álvarez-Sanchís, J.R., Lorrio Alvarado, A.J., Ruiz Zapatero, G., 2016. Los primeros elementos de hierro en Iberia. Cuadernos de Prehistoria y Arqueología de la Universidad Autónoma de Madrid- Anejos 2, 149-165.

Arnáiz Alonso, M.A., 2017. La I Edad del Hierro en la cuenca media del Duero: arquitectura doméstica y formas de poder político durante la facies Soto (siglos IX-VII a.C.). Trabajos de Prehistoria 74(1), 86-107.

Barril Vicente, M., Galán Domingo, E., (Eds.), 2007. Ecos del Mediterráneo. El mundo ibérico y la cultura vettona. Diputación de Ávila, Madrid.

Belarte, M.C., 2002. La construcció amb terra a la protohistòria. Societat Catalana d'Arqueologia, Barcelona.

Benet Jordana, N., 2001. La ciudad de Salamanca. De su formación a la Repoblación. In: Salamanca Ciudad Europea de la Cultura 2002, 15-43. Consorcio Salamanca 2002, Salamanca.

Benet, N., López Jiménez, O., 2008. Investigaciones recientes en la Edad del Hierro en Salamanca y la Beira Alta: Ios castros del occidente. In: Álvarez-Sanchís, J.R. (Ed.), Arqueología Vettona. La Meseta Occidental en la Edad del Hierro, 162-181. Museo Arqueológico Regional, Alcalá de Henares.

Benet, N., Jiménez, M.C., Rodríguez, M.B., 1991. Arqueología en Ledesma; una primera aproximación: la excavación de la plaza de San Martín. In: Santonja, M. (Coord.), Del Paleolítico a la Historia, 117-137. Museo de Salamanca, Salamanca.

Blanco García, J.F., 2017. Los pueblos prerromanos del interior peninsular y los territorios atlánticos. In: Celestino Pérez, S. (Coord.), Historia de España II. La Protohistoria en la península Ibérica, 647-811. Istmo, Madrid.

Blanco-González, A., Alario García, C., Macarro Alcalde, C., 2017. The earliest villages in Iron Age Iberia (800-400 BC): a view from Cerro de San Vicente (Salamanca, Spain). Documenta Praehistorica XLIV, 386-401.

Blasco Bosqued, M.C., Alonso, M.A., Lucas Pellicer, M.R., 1991. Excavaciones en el poblado de la Primera Edad del Hierro del Cerro de San Antonio. Arqueología, Paleontología y Etnografía 2, 7-187.

Casado Ariza, M., 2015. La cerámica con decoración geométrica del Carambolo. Universidad de Sevilla, Sevilla.
Celestino Pérez, S., (Ed.), 1996. El palacio-santuario de Cancho Roano V-VI-VII. Los sectores oeste, sur y este. Museo de Badajoz, Badajoz.

Celestino Pérez, S., 2001. Los santuarios de Cancho Roano. Del indigenismo al orientalismo arquitectónico. In: Ruiz Mata, D., Celestino Pérez, S. (Eds.), Arquitectura oriental y orientalizante en la Península Ibérica, 17-56. Consejo Superior de Investigaciones Científicas, Mérida.

Celis Sánchez, J., 1993. La secuencia del poblado de la Primera Edad del Hierro de 'Los Cuestos de la Estación', Benavente (Zamora). In: Romero Carnicero, F., Sanz Mínguez, C., Escudero Navarro, Z. (Eds.), Arqueología Vaccea. Estudios sobre el mundo prerromano en la cuenca media del Duero, 93-132. Junta de Castilla y León, Valladolid.

Dávila, A.F., (Ed.) 2007. Estudios sobre la Edad del Hierro en la Carpetania. Zona Arqueológica 10. Museo Arqueológico Regional, Alcalá de Henares.

Delibes de Castro, G., Romero Carnicero, F., Morales Muñiz, A., (Eds.), 1995a. Arqueología y medio ambiente. El primer milenio a.C. en el Duero Medio. Junta de Castilla y León, Valladolid.

Delibes de Castro, G., Romero Carnicero, F., Ramírez Ramírez, M.L., 1995b. El poblado 'céltico' de El Soto de Medinilla (Valladolid). In: Delibes de Castro, G., Romero Carnicero, F., Morales Muñiz, A. (Eds.), Arqueología y medio ambiente. El primer milenio a.C. en el Duero Medio, 149-177. Junta de Castilla y León, Valladolid.

Delibes de Castro, G., Romero Carnicero, F., 2011. La plena colonización agraria del Valle Medio del Duero. In: Álvarez-Sanchís, J.R., Jimeno Martínez, A., Ruiz Zapatero, G. (Eds.), Aldeas y ciudades en el primer milenio a.C. La Meseta Norte y los orígenes del urbanismo, Complutum 22 (2), 49-94. Universidad Complutente de Madrid, Madrid.

Díes Cusí, E., 2001. La influencia de la arquitectura fenicia en las arquitecturas indígenas de la Península Ibérica (ss. VIII-VII). In: Ruiz Mata, D., Celestino Pérez, S. (Eds.), Arquitectura oriental y orientalizante en la Península Ibérica. 69-121. Consejo Superior de Investigaciones Científicas, Mérida.

Esparza Arroyo, A., 1995. La Primera Edad del Hierro. In: Alba, J.C. (Coord.), Historia de Zamora, I, De los Orígenes al Final del Medievo, 101-150. Diputación de Zamora, Zamora.

Esparza Arroyo, A., 2011. Los castros del oeste de la Meseta. In: Álvarez-Sanchís, J.R., Jimeno Martínez, A., Ruiz Zapatero, G. (Eds.), Aldeas y ciudades en el primer milenio a.C. La Meseta Norte y los orígenes del urbanismo, Complutum 22 (2), 11-48. Universidad Complutente de Madrid, Madrid.

Esparza Arroyo, A., Velasco Vázquez, J., Celis Sánchez, J., 2016. Notas sobre la fase Soto formativo en el poblado de los Cuestos de la Estación (Benavente, Zamora). Boletín del Seminario de Arte y Arqueología - Arqueología LXXXII, 63-85.

Fernández-Posse, M.D., 1998. La investigación protohistórica en la Meseta y Galicia. Síntesis, Madrid.

Fernández-Posse, M.D., Sánchez-Palencia, F.J., 1998. Las comunidades campesinas en la Cultura Castreña. Trabajos de Prehistoria 55(2), 127-150.

Gillani, G., Santonja, M., (Eds.), 2007. Arqueología en la Vía de la Plata (Salamanca). Fundación Premysa, Salamanca.

Gilman, A., 1995. Prehistoric European Chiefdoms. Rethinking 'Germanic' Societies. In: Price, T. D., Feinman, G.M. (Eds.), Foundations of Social Inequality, 235-251. Plenum Press, New York. 
González García, F.J., Parcero-Oubiña, C., Ayán Vila, X., 2011. Iron Age societies against the State: an account of the emergence of the Iron Age in North-western Iberia. In: Moore, T., Armada, X-L. (Eds.), Atlantic Europe in the First Millenium BC: Crossing the Divide, 285-301. Oxford University Press, Oxford.

González-Ruibal, A., 2006-7. Galaicos. Poder y Comunidad en el Noroeste de la Península Ibérica (1200 a.C.-50 d.C). Museo Arqueolóxico e Histórico de San Antón, A Coruña.

González-Ruibal, A., 2009. Economía política y tecnología del espacio: 'sociedades de casa' en el noroeste de la Península Ibérica (s. II a.C.-I d.C.). In: Belarte, C. (Ed.), L'espai domèstic i la organització de la societat a la protohistòria de la Mediterrània occidental (Ier mil•leni a.C.), 225-243. Arqueomediterrània, Barcelona.

González-Ruibal, A., Ruiz-Gálvez, M., 2016. House Societies in the Ancient Mediterranean (2000-500 BC). Journal of World Prehistory 19, 383-437.

González-Tablas, F.J., 1990. La necrópolis de 'Los Castillejos' de Sanchorreja. Su contexto histórico. Universidad de Salamanca, Salamanca.

Hamilton, W.D., Haselgrove, C., Gosden, C., 2015. The impact of Bayesian chronologies on the British Iron Age. World Archaeology 47(4), 642-660.

Heredero García, R., 1993. Casas circulares y rectangulares de época vaccea en el yacimiento del Cerro del Castillo (Montealegre). In: Romero Carnicero, F., Sanz Mínguez, C., Escudero Navarro, Z. (Eds.), Arqueología Vaccea. Estudios sobre el mundo prerromano en la cuenca media del Duero, 279-302. Junta de Castilla y León, Valladolid.

Jiménez Jáimez, V., 2008. El ciclo formativo del registro arqueológico. Una alternativa a la dicotomía deposicional/posdeposicional. Zephyrus 62(2), 125-137.

LaMotta, V., Schiffer, M.B., 1999. Formation processes of house floor assemblages. In: Allison, P. (Ed.), The Archaeology of Household Activities, 19-29. Routlegde, London.

López Jiménez, O., 2011. Estructura social y formas de ocupación del territorio en el occidente de la Meseta Norte en el I milenio a.C. In: Ruiz Zapatero, G., Álvarez-Sanchís, J.R. (Eds.), Castros y verracos. Las gentes de la Edad del Hierro en el occidente de Iberia, 243-268. Institución Gran Duque de Alba, Ávila.

Macarro Alcalde, C., 1999. El primitivo asentamiento de Salmantica: aportaciones al conocimiento de la Cultura del Soto en el valle del Tormes. Memoria de Licenciatura. Universidad de Salamanca, Salamanca.

Macarro Alcalde, C., 2014. La actividad comercial e industrial de Salmantica en la Edad del Hierro a través de la Arqueología. In: García-Figuerola, M. (Coord), Historia del comercio y la industria de Salamanca y provincia (Actas de las V Jornadas celebradas en el Museo del Comercio), 39-68. Museo del Comercio y la Industria de Salamanca, Salamanca.

Macarro Alcalde, C., Alario García, C., 2012. Los Orígenes de Salamanca. El poblado protohistórico del Cerro de San Vicente. Centro de Estudios Salmantinos, Salamanca.

Maluquer de Motes, J., 1951. De la Salamanca Primitiva. Zephyrus II, 61-72.

Martín Valls, R., 1998. La Edad del Hierro. In: Salinas de Frías, M. (Coord.), Historia de Salamanca I, Prehistoria y Edad Antigua, 123-217. Centro de Estudios Salmantinos, Salamanca.

Martín Valls, R., Benet Jordana, N., Macarro Alcalde, C., 1991. Arqueología de Salamanca. In: Santonja Gómez (Coord.), Del
Paleolítico a la Historia, 137-163. Junta de Castilla y León, Salamanca.

Misiego Tejeda, J.C., Martín Carbajo, M.A., Marcos Contreras, G.J., Sanz García, F.J., Pérez Rodríguez, F.J., Doval Martínez, M., Villanueva Martín, L. A., García Rivero, P.F., García Martínez, M.I., Redondo Martínez, R., Ollero Cuesta, R., Sánchez Bonilla, G., 2013. Las excavaciones arqueológicas en el yacimiento de 'La Corona/El Pesadero', en Manganeses de la Polvorosa. La Edad del Hierro y la época romana en el norte de la provincia de Zamora. Junta de Castilla y León, Valladolid.

Morín, J., Urbina, D., (Eds.), 2012. El primer milenio a.C. en la Meseta Central. De la 'longhouse' al oppidum. Audema, Madrid.

Palol, P., Wattenberg, F., 1974. Carta Arqueológica de España. Valladolid. Diputación de Valladolid, Valladolid.

Parcero Oubiña, C., 2002. La construcción del Paisaje Social en la Edad del Hierro del Noroeste Ibérico. Fundación F.M. Ortegalia, Ortigueira.

Picazo, J.V., Rodanés, J.M., 2009. Los Poblados del Bronce Final y Primera Edad del Hierro del Cabezo de la Cruz (La Muela, Zaragoza). Gobierno de Aragón, Zaragoza.

Reimer, P.J., Bard, E., Bayliss, A., Beck, J.W., Blackwell, P.G., Bronk Ramsey, C., Buck, C.E., Cheng, H., Edwards, R.L., Friedrich, M., Grootes, P.M., Guilderson, T.P., Haflidason, H., Hajdas, I., Hatté, C., Heaton, T.J., Hoffmann, D.L., Hogg, A.G., Hughen, K.A. Kaise, K.F., Kromer, B., Mannining, S.W., Niu, M., Reimer, R.W., Richards, D.A., Scott, M., Southon, J.R., StaffF, R.A., Turney, C.S.M., Van Der Plicht, J., 2013. Intcal13 and Marine13 radiocarbon age calibration curves $0-50,000$ years cal BP. Radiocarbon 55, 1869-1887.

Rodríguez Díaz, A., (Ed.) 2004. El Edificio protohistórico de la 'La Mata' (Campanario, Badajoz) y su estudio territorial. Universidad de Extremadura, Cáceres.

Rodríguez Díaz, A., Pavón Soldevila, I., Duque Espino, D.M., (Eds.), 2009. El Caserío de Cerro Manzanillo (Villar de Rena, Badajoz) y la colonización agraria orientalizante en el Guadiana Medio. Memorias de Arqueología Extremeña, 12. Junta de Extremadura, Mérida.

Rodríguez Díaz, A., Pavón Soldevila, I., Duque Espino, D.M., (Eds.) 2015a. El Tiempo del Tesoro de Aliseda, II. Aproximación a su contexto arqueológico. Tagus Asociación para el Desarrollo Integral Tajo-Salor - G.I. PRETAGU, Cáceres.

Rodríguez Díaz, A., Pavón Soldevila, I., Duque Espino, D.M., 2015b. Jerarquía y heterarquía en las cuencas extremeñas del Guadiana y Tajo durante el Período Orientalizante. In: Belarte, M.C., Garcia, D., Sanmartí, J. (Eds.), Les estructures socials protohistòriques a la Gàl•lia i a Ibèria. Homenatge a Aurora Martín i Enriqueta Pons, 295-313. Aqueomediterrània 14, Barcelona.

Romero Carnicero, F., 1992. Los antecedentes protohistóricos. Arquitectura de piedra y barro durante la primera Edad del Hierro. In: Báez Mezquita, J.M. (Coord.), Arquitectura popular de Castilla y León. Bases para un estudio, 175-211. Junta de Castilla y León, Valladolid.

Romero Carnicero, F., Cubero Corpas, C., 1999. Agricultura y recolección en la cultura del Soto (Primera Edad del Hierro en el valle medio del Duero). In: Buxó, R., Pons, E. (Dirs.), Els productes alimentaris d'origen vegetal a l'Etat del Ferro de l'Europa Occidental: de la producció al consum, 169-187. Museu d'Arqueologia de Catalunya, Girona.

Romero Carnicero, F., Misiego Tejeda, J.C., Marcos Conterras, G.J., 2015. La presencia de defensas en los poblados de la cultura del Soto: una evidencia cada vez menos excepcional. In: Rodríguez, O., Portilla, R, Sastre, J.C., Fuentes, P. (Coords.), Fortificaciones en la Edad del Hierro: control de los recursos y el territorio, 547-564. Glyphos, Madrid. 
Romero Carnicero, F., Ramírez Ramírez, M.L., 1996. La cultura del Soto. Reflexiones sobre los contactos entre el Duero Medio y las tierras del sur peninsular durante la Primera Edad del Hierro. In: Querol, M.A., Chapa, T. (Eds.), Homenaje al Profesor Manuel Fernández-Miranda. Complutum Extra, 6, Tomo II, 313-326. Universidad Complutense de Madrid, Madrid.

Romero Carnicero, F., Sanz Mínguez, C., Álvarez-Sanchís, J.R., 2008. El primer milenio A.C. en las tierras del interior peninsular. In: Gracia, F. (Coord.), De Iberia a Hispania, 649-732. Ariel, Barcelona.

Ruiz-Gálvez, M., 1992. La novia vendida: orfebrería, herencia y agricultura en la protohistoria de la Península Ibérica. Spal 1, 219-251.

Ruiz-Gálvez, M., 1998. La Europa atlántica en la Edad del Bronce. Un viaje a las raíces de la Europa occidental. Crítica, Barcelona.

Ruiz Zapatero, G., 2007. Antes del Hierro. Cultura y Sociedad en el centro de la Meseta (ca. 1200-500 a.C.). In: Dávila A.F. (Ed.), Estudios sobre la Edad del Hierro en la Carpetania, Zona Arqueológica 10, Vol. 1, 36-62. Museo Arqueológico Regional, Alcalá de Henares.

Ruiz Zapatero, G., 2009. Casas, comunidades y tipos de sociedad en el área céltica peninsular. In: Belarte, C. (Ed.), L'espai domèstic i la organització de la societat a la protohistòria de la Mediterrània occidental (Ier mil•leni a.C.), 225-243. Arqueomediterrània, Barcelona.

Ruiz Zapatero, G., 2013. La excavación arqueológica. In: García-Díez, M., Zapata, L. (Eds.), Métodos y técnicas de análisis y estudio en arqueología prehistórica. De lo técnico a la reconstrucción de los grupos humanos, 39-72. Universidad del País Vasco, Bilbao.
Ruiz Zapatero, G., Álvarez-Sanchís, J.R., 2015. ¿Centros de poder? Sociedad y poblamiento en la Meseta Norte española (ca. 800 - 400 a.C.). Vegueta 15, 211-233.

Sánchez Alonso, E., 2015. Inhumaciones infantiles en ambientes domésticos de la Edad del Hierro en el valle del Duero. Trabajo de Fin de Grado. Universidad de Valladolid, Valladolid.

Sastre, I., Currás, B.X., Alonso, F., 2010. Parentesco, desigualdad y formas de identidad en la Edad del Hierro del Noroeste. In: Burillo, F. (Ed.), Arqueología de la Población. Arqueología Espacial 28, 169-186. Seminario de Arqueología y Etnología Turolense, Teruel.

Seco Villar, M., Treceño Losada, F.J., 1993. La temprana 'iberización' de las tierras del sur del Duero a través de la secuencia de 'La Mota', Medina del Campo (Valladolid), In: Romero Carnicero, F., Sanz Mínguez, C., Escudero Navarro, Z. (Eds.), Arqueología Vaccea. Estudios sobre el mundo prerromano en la cuenca media del Duero, 133-171. Junta de Castilla y León, Valladolid.

Schiffer, M.B., 1987. Formation Processes of the Archaeologic Record. University of Utah Press, Salt Lake City.

Stevanović, M., 1997. The age of clay: The social dynamics of house destruction. Journal of Anthropological Archaeology 16, 334-395.

Torres Rodríguez, J., 2013. La Tierra sin Límites. Territorio, Sociedad e Identidades en el Valle Medio del Tajo (s. IX-I a.C.). Museo Arqueológico Regional, Madrid.

Vives-Ferrándiz, J., 2006. Negociando encuentros. Situaciones coloniales e intercambios en la costa oriental peninsular (ss. VIII-VI a.C.). Cuadernos de Arqueología Mediterránea 12. Bellaterra, Barcelona. 